University of Louisville ThinkIR: The University of Louisville's Institutional Repository

Electronic Theses and Dissertations

$5-2016$

\title{
An evaluation of Multiple Endmember Spectral Mixture Analysis applied to Landsat 8 OLI images for mapping land cover in southern Africa's Savanna.
}

Fernando Ferreira Caixeta

University of Louisville

Follow this and additional works at: https://ir.library.louisville.edu/etd

Part of the Remote Sensing Commons

\section{Recommended Citation}

Caixeta, Fernando Ferreira, "An evaluation of Multiple Endmember Spectral Mixture Analysis applied to Landsat 8 OLI images for mapping land cover in southern Africa's Savanna." (2016). Electronic Theses and Dissertations. Paper 2419.

https://doi.org/10.18297/etd/2419 for inclusion in Electronic Theses and Dissertations by an authorized administrator of ThinkIR: The University of Louisville's Institutional Repository. This title appears here courtesy of the author, who has retained all other copyrights. For more information, please contact thinkir@louisville.edu. 


\title{
AN EVALUATION OF MULTIPLE ENDMEMBERS SPECTRAL MIXTURE ANALYSIS APPLIED TO LANDSAT 8 OLI IMAGES FOR MAPPING LAND COVER IN SOUTHERN AFRICA'S SAVANNA
}

\section{By}

Fernando Ferreira Caixeta

B.A, Universidade de Brasília, 2007

\begin{abstract}
A Thesis Submitted to
the Faculty of the College of Arts and Sciences of the University of Louisville in Partial Fulfillment of the Requirements for the Degree of
\end{abstract}

Master of Science in Applied Geography

Department of Geography and Geosciences

University of Louisville

Louisville, Kentucky

May 2016 



\title{
AN EVALUATION OF MULTIPLE ENDMEMBER SPECTRAL MIXTURE ANALYSIS APPLIED TO LANDSAT 8 OLI IMAGES FOR MAPPING LAND COVER IN SOUTHERN AFRICA'S SAVANNA
}

\author{
By
}

Fernando Ferreira Caixeta

B.A. Universidade de Brasília, 2007

A Thesis Approved on

April 22, 2016

by the following Thesis Committee:

Dr. Andrea E. Gaughan

Dr. Forrest R. Stevens

Dr. Margaret Carreiro 


\section{DEDICATION}

This thesis is dedicated to my parents

Margarida and Pedro

Who have given me invaluable educational opportunities and continuous care. 


\section{ACKNOWLEDGEMENTS}

I am thankful to God for the good health and wellbeing necessary to complete this thesis. Also, I wish to express my most sincere gratitude to Dr. Andrea Gaughan, who patiently and dedicatedly guided me through my research, never hesitating in sharing her knowledge and wisdom. I would like to thank Dr. Forrest Stevens, who give me valuable support as my co-mentor. I also take this opportunity to thank Dr. Margaret Carreiro for agreeing to participate in my thesis committee and for her courtesy towards me. Thanks to all the colleagues, friends, faculty and staff of the Department of Geography and Geosciences with whom I've shared paths in this unforgettable part of my journey (y'all will be forever in my heart). To my family that, even at distance, never abandoned me and provided great support with words of encouragement. I am also immensely grateful to my wife and love of my life, Iara, who was always there cheering me up and stood by me through the good times and bad. Finally, thanks to one and all that somehow contributed to the writing of this thesis. 


\begin{abstract}
AN EVALUATION OF MULTIPLE ENDMEMBER SPECTRAL MIXTURE ANALYSIS APPLIED TO LANDSAT 8 OLI IMAGES FOR MAPPING LAND COVER IN SOUTHERN AFRICA'S SAVANNA
\end{abstract}

Fernando F. Caixeta

May 14, 2016

Mapping land cover in southern Africa's savannas using traditional pixel based remote sensing techniques can be very challenging due to the heterogeneity of its vegetation structure and the spectral difficulty in separating similar land covers across various land uses. In order to overcome these complications, a Multiple Endmember Spectral Mixture Analysis (MESMA) provides a potential remote sensing approach to quantify spectral variation in the physical environment at a subpixel level. The MESMA approach was applied in the study area of the Mayuni Conservancy, in Namibia. Results show that $32.3 \%$ of the study area is covered by photosynthetic vegetation (PV), 32.0\% by nonphotosynthetic vegetation (NPV), $25.2 \%$ by bare soil (B) and $10.6 \%$ by shade. Postclassification validation shows that MESMA presented a moderate performance in estimating the proportions of land cover types in the study area. However the validation process is limited to the available resources and carries great subjectivity. It is concluded that future research on the matter should include a more consistent investigation on the endmember selection methodology and expand the study area inside of the same ecosystem. 
TABLE OF CONTENTS

PAGE

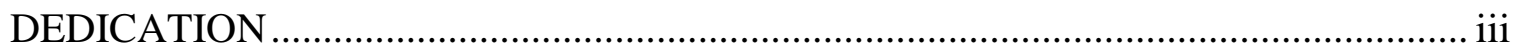

ACKNOWLEDGEMENTS .................................................................................. iv

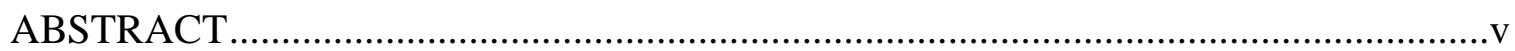

LIST OF FIGURES ……..................................................................................... vii

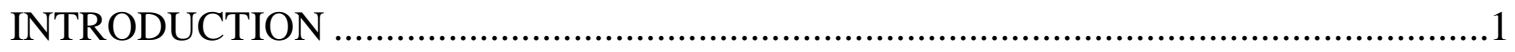

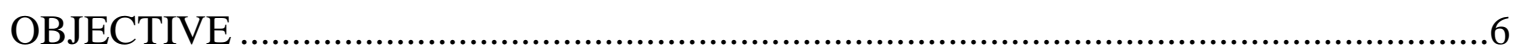

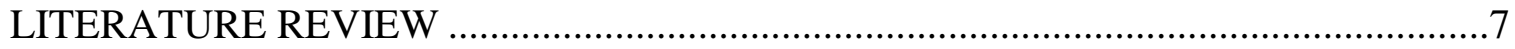

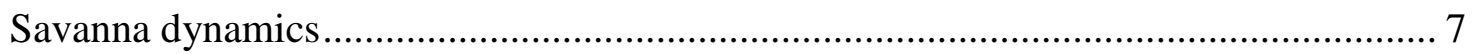

The Multiple Endmember Spectral Mixture Analysis (MESMA)................................ 10

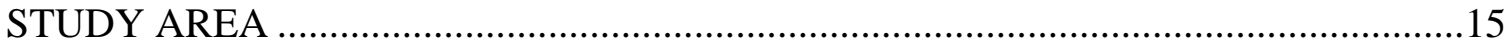

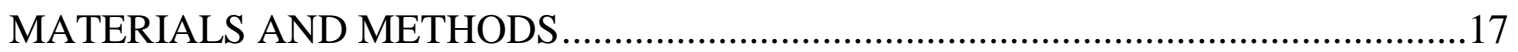

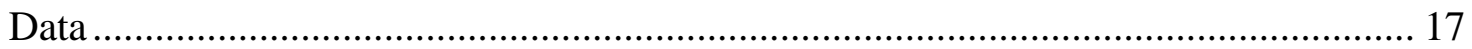

The spectral mixing model...................................................................................... 20

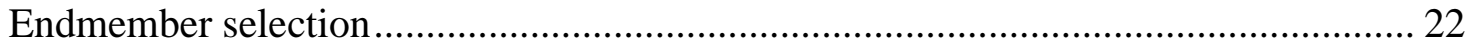

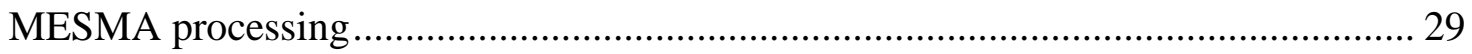

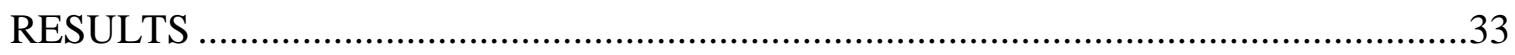

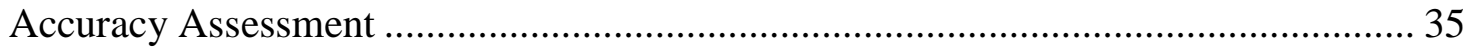

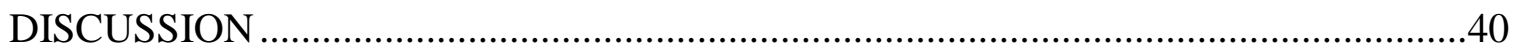




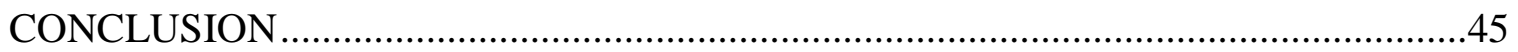

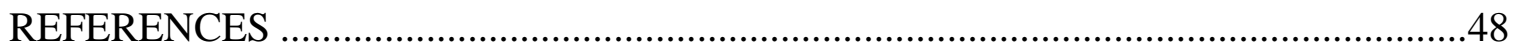

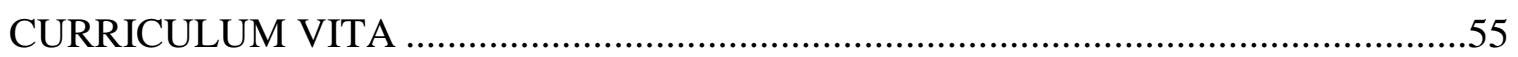




\section{LIST OF FIGURES}

\section{FIGURE}

PAGE

1. Study's area location.

2. Linear spectral mixing model for a single pixel and application of SMA equation

(Jensen 2014, adapted)

3. Scatterplot of hypothetical bands 1 and 2, showing endmembers A, B and C.

4. Representation of the spatial relationship between the first two principal components in a scatterplot of two hypothetical bands, where $\mathrm{PC}_{1}$ is the principal component 1 and $\mathrm{PC}_{2}$

is the principal component 2 .

5. MNF eigenvalues plot, where the vertical axis shows the eigenvalues and the horizontal axis show the eigenvalue number, which corresponds to MNF bands order. ..25

6. MNF bands, where a) correspond to band 1, b) to band 2, and so on. .26 7. N-dimensional visualizer, where the dots represent the pixels from PPI calculation and the axis correspond to the first $3 \mathrm{MNF}$ bands.

8. Worldview-2 image fragment showing the aspects of woodland/shrubland (PV),

grassland (NPV) and bare soil (B).

9. Landsat 8 and Worldview-2 images geographically linked together. The red squares in the Worldview-2 images correspond to the content of the pixel in the crosshair on the Landsat 8 counterpart.

10. Spectral libraries showing the spectral signatures of PV, NPV and B endmembers...30

11. Resulting fraction image in a B, NPV,PV RGB composite. 34 
12. Individual fraction images obtained from MESMA, where a) represents PV; b), NPV; c), B; and d) shade .35

13. Image showing the RMSE distribution across the mapped area..............................36 14. Sample points distributed inside an area that represents a single fraction image's pixel, where red, green, blue and yellow dots are B, NPV, PV and shade sample points, respectively.

15. Scatterplots depicting the relationship between the results obtained with MESMA and those generated in the validation process, with 1:1 line as a reference of perfect positive correlation. .38 


\section{INTRODUCTION}

Occupying vast areas between the equatorial forests and the mid-latitude deserts, savannas have ecological characteristics, neither those of a forest, nor those of a grassland. The unique character of this kind of vegetation is given by strong and complex interactions between woody and herbaceous plants. Indeed, in no other major terrestrial biome is primary production so equitably shared between trees and grasses (Scholes and Walker 2004). Tropical savannas cover about 1.6 million hectares, which represents one eighth of Earth's land surface. They cover more than half of the area of Africa and Australia, $45 \%$ of South America, and $10 \%$ of India and Southeast Asia, containing a large and rapidly growing proportion of the world's human population and the majority of its rangelands and livestock. At the same time, savannas are among the most remarkable vegetation types, where contrasting plant species thrive, side by side, in codominance relationships (Scholes and Archer 1997).

At the global scale, tropical savannas play a major role in land-atmosphere energy balance. The arid and semi-arid savanna systems in southern Africa are important contributors to biomass productivity and biodiversity, containing some of the largest wildlife habitats, and offering a basis for the development of economic activities (Stott 1991). Savannas are heterogeneous in structure and present diverse systems that differ functionally from each other. The morphology of savanna vegetation varies from dense shrubland and woodland to open grassland with little shrub cover, as well as intermediate gradients of plant density (Sankaran et al. 2005). These savanna systems are undergoing 
large-scale structural and functional changes, as a result of increasing anthropogenic pressure, changing land use, altered fire regimes andclimatic shifts (Adeel, De Kalbermatten, and Assessment 2005). Such changes are affecting biogeochemical processes as well as the availability of habitat-related key structural resources, such as foraging grounds and migration routes (Blaum, Rossmanith, and Jeltsch 2007).

The understanding of spatio-temporal variation in savannas' ecological processes is fundamental to decision-making concerning land use/cover aiming to promote longterm sustainability of these dynamic and fragile systems. This understanding is dependent on the ability to quantitatively characterize and monitor savanna attributes, like the density and condition of vegetation cover (Guerschman et al. 2009). To understand these ecological mechanisms at a regional scale, it is necessary that information about the land cover of the area be collected and measured. Since remote sensing techniques and practices are focused on detecting phenomena occurring in Earth's surface, they provide a very efficient toolkit to perform the proposed task. In the past few decades, new satellites and sensors began to operate, increasing the application possibilities of these devices (Sande, Jong and Roo 2003; Toutin 2004; Kulkarni et al. 2006; Eitel et al. 2007; Smith and Pain 2009; Ehlers et al. 2010; Lim et al. 2010; Kruse and Perry 2013; Shang et al 2015). The technological advance in this field is accompanied by the popularization of remote sensing and a large increment of available data.

Remote-sensing-based characterization of land cover in semi-arid savanna systems is challenging for several reasons: a high soil background leading to minimization of the spectral contribution of plants; lack of a strong red edge and reduced absorption in visible wavelengths due to evolutionary adaptation of semi-arid vegetation; 
and the potential for non-linear mixing in arid and semi-arid areas due to multiple scattering and high spectral variability within individuals of similar species (Okin et al. 2001). Also, the heterogeneity of savannas can lead to a mixing of diverse vegetation cover types within a single pixel, resulting in spectral signatures that are difficult to classify (Jung et al. 2006). Besides those issues, mapping land cover in savannas can be problematic due to mixing among different land cover categories or dominance of transitional classes including shrublands or herbaceous vegetation (Herold et al. 2008). Such difficulties are not exclusive of African savannas, being a problem for South American ones as well. Spectral similarities between cropland, pasture and natural savanna vegetation, and a high spectral heterogeneity within each land cover type, complicate the differentiation of land use/cover in the Brazilian Cerrado (Müller et al. 2015).

One of the key aspects to consider while assessing land cover is the 'greenness' of the area's vegetation. In remote sensing, green vegetation traditionally has been quantified based on vegetation indices (VIs), with the Normalized Difference Vegetation Index (NDVI) being the most common VI (Nagler et al. 2003). Although VIs have been used with this purpose, they have been criticized for only providing a proxy of plant cover, not an estimate of total vegetation cover (Yang, Weisberg, and Bristow 2012). In fact, these indices measure vegetation productivity but do not represent its structural characteristics. To improve upon the limitation of VIs, some studies have adopted an alternative technique called Spectral Mixture Analysis (SMA), which is less affected by soil background effects (Garcia-Haro, Gilabert and Melia 1996). The technique provides subpixel abundance estimates based on the assumption that the spectral signature of a 
pixel is a linear, proportion-weighted combination of endmembers (Asner and Lobell 2000). In comparison to traditional pixel-based classification methods, the SMA approach determine and report the actual proportion of the pure and homogeneous materials within the pixel instead to assign a pixel to a single class (Jensen 2014). In this sense SMA techniques are capable of providing a more nuanced quantification of land cover classes in relation to pixel-based classification methods. Since the accuracy of SMA-derived land cover estimates are highly dependent on endmember purity, this model may fail to account for natural variability in the reflectance of endmembers. Multiple endmember spectral mixture analysis (MESMA) addresses this issue by allowing both the type and number of endmember models to vary on a per-pixel basis (Roberts et al. 1998).

MESMA has been widely utilized with hyperspectral images for deriving land cover estimates in several ecosystems, including xeric ones (Okin et al. 2001; Asner and Heidebrecht 2002; Franke et al. 2009; Somers et al. 2009; Somers et al 2010 and Blanco et al 2014). Although hyperspectral data provides detailed reflectance information for land cover mapping using MESMA, their utility is restricted due to limited spatial coverage and data, especially over southern African savannas. In contrast, multispectral remote-sensing products at medium spatial resolutions provide synoptic spatial extent and repeated coverage, but lack spectral sensitivity and ideal bands in the Short Wave Infrared (SWIR) band, where differentiation of non-photosynthetic vegetation (e.g. dormant grasses) from soil is most effective (Mishra, Crews, and Okin 2014). Indeed, there is a tradeoff between spectral and spatial resolutions among hyperspectral and multispectral data. Scenes of images with hyperspectral character have a smaller spatial 
extent, while multispectral data is capable to cover the same area in a repeated and consistent manner. Despite the spectral disadvantage of multispectral images, MESMA has been successfully applied to this kind of data, especially concerning Landsat imagery (Powell et al. 2007; Somers et al. 2010; Fernández-Manso, Quintano and Roberts 2012; Wu, Deng and Jia 2014; Nogueira et al. 2015; Robertson, King and Davies 2015). Identifying remote sensing techniques that more accurately quantify savanna land cover is of great importance due to the unique ecologic characteristics of these areas and their vast distribution across the globe. The current improvements in remote sensing products and techniques provide new tools to accomplish this task. This study addresses the following overarching question: Is MESMA adequate for generating land-cover maps in southern Africa's savanna using multispectral images. The hypothesis is that the results obtained with MESMA are effective in depicting the fractional land cover of the study area in a subpixel level. 


\section{OBJECTIVE}

The objective of this research is to obtain fractional images by applying MESMA to Landsat 8 OLI imagery in order to assess the proportions of photosynthetic vegetation (PV), non-photosynthetic vegetation (NPV) and bare soil (B) in the study area. PV and NPV are represented by woodlands/shrublands and grasslands, respectively. Fractional images are outputs of MESMA and are formed by pixels that contain information about the areal proportions of pure homogeneous materials, also known as endmembers, with one image for each endmember spectrum (Jensen 2014). The data collection took place in the dry season of 2014 in southern Africa, when the grasses were senescent and trees and shrubs were green (Scholes and Archer 1997). 


\section{LITERATURE REVIEW}

\section{$\underline{\text { Savanna dynamics }}$}

The prevailing ecological usage of the term savanna denotes communities or landscapes with a continuous grass layer and scattered trees. This combination of contrasting vegetation physiognomies, together with an accentuated difference between

dry and wet seasons in tropical and subtropical regions, distinguishes savanna's function and structure from those observed in forests, grasslands and deserts. The savanna's vegetation patterns are driven by many environmental factors such as herbivory, fire, climate, and soils, as well as by anthropic activities. The spatial arrangement and relative abundance of grasses and woody plants in these areas are dictated by complex and dynamic interactions among environmental and anthropogenic factors. In this sense, natural factors interact with each other and with anthropogenic elements, making it difficult to identify, isolate or quantify the key determinants of the vegetation structure (Sholes and Archer 1997). In this section, some of the influential factors that drive the structure of savannas' vegetation are explored to bring some light on the elements that contribute to the dynamics of savanna systems.

Dwelling within African savannas are some of the largest and most spectacular megafauna, which functions as a major driver of savanna's structure. Large herbivores disturb plant communities at many levels, varying from major effects resulting in noticeable changes to plant community composition and structure, to plant-herbivore interactions leading to stable subclimaxes when fauna and flora coexist in relative 
balance. In a deeper manner, the herbivore's influence manifests by co-evolutionary relationships, such as those concerning plants' defense systems that may employ thorns, poisons or phenological strategies, such as irregular or infrequent fruiting (Cumming 1982). For African savannas, the scholars agree that there is a tendency for grazers to enhance woody cover and browsers and mixed feeders to depress it in local or regional contexts, but those effects seem inconspicuous on a continental scale (Sankaran et al. 2005).

Savannas are classified as flammable ecosystems and are the most frequently burnt environments in the world, with fires occurring from several times a decade to twice a year. These areas present higher primary productivity and greater aridity when compared to other kinds of vegetation, which leads to the buildup of high quantities of dry fuel and, consequently, to high fire frequencies and intensities. In such habitats fires tend to consume the herbaceous surface biomass but leave the dominant trees untouched (Bond and Keeley 2005). McNaughton (1983) observed a decline in herb and grass biodiversity in both fire-protected areas and repeatedly burnt ones, in the Serengeti, indicating that fire is a major factor in savannas' ecology. The same study points out that fire also has a direct and substantial effect on the recruitment of seedlings into the community, indicating that burning has an effect beyond the simple removal of plant cover. The phenomenon also influences how animal effects interact with burning to increase seedling density levels. In this sense, hoof-prints made in moist soil, which function as recruitment sites, presented significantly higher germination rates in burnt areas when compared to their surroundings. 
The climate in tropical savannas is characterized by the alternating of warm dry seasons with hot wet seasons. The responsive behavior of savannas' flora to climate is strongly related to rain regimes, with deciduous trees achieving full leaf expansion within weeks of the beginning of the rainy season, while $\mathrm{C}_{4}$ grasses reach the peak leaf area several months after the start of the wet season. In arid environments of unpredictable nature and dominated by minor rainfall occurrences, the opportunistic strategy of grasses is favored, whereas in unremittingly moist environments, overtopping strategy is favored. In this sense, for savanna environments, there is a greater advantage for trees over grasses in the moister regions. So, it is noticeable that the structure of African savannas is affected by climate, especially regarding rainfall and moisture availability (Scholes and Archer 1997).

Soil texture and fertility are important drivers of savanna vegetation structure, since they are key determinants of the availability of water and nutrients, affecting the treegrass-shrub proportion. Trees favor areas where the soil has a low water-holding capacity, such as sandy ones, since in these soils the water availability is greater in their deeper layers, where tree rooting depth is advantageous. Contrariwise, shallow soils over impervious layers and water retaining clays are not favorable to trees, instead trending to grass dominance. Such a dynamic takes place, mainly, because trees have deeper roots than grasses, being able to reach the water supply in such conditions. Fertile soils, in turn, support vigorous grass growth. In such environments, extensive grassland patches can occur, suggesting a robust constancy of their state. However, these areas can be invaded by trees when tree propagules are present and the grass cover is reduced. Low fertility soils are rarely treeless, suggesting a very weak or absent meta-stable grassland state, 
while fertile clayey soils were relatively treeless in precolonial times. Thus, soil acts as one of the main elements on resource partitioning patterns, accounting, largely, for primary production rates (Scholes and Archer 1997).

The structure of savanna's vegetation is, in fact, driven by the interaction of a diversity of stresses and disturbances, acting differentially on trees and grasses and varying complexly through time and space, creating shifting ecotones that can make remote-sensing based assessments difficult for these areas. Moreover, the characteristics of these environmental drivers are affected by human activities. Anthropogenic factors contributed to events such as a dramatic increase of fire rates since pre-historic times and the overgrazing caused by the introduction of livestock (Scholes and Archer 1997).

Such dynamics contributes to the formation of a very heterogeneous landscape, which makes that the mixing of different types of vegetation within a single pixel a frequent occurrence (Jung et al. 2006). In this regard, traditional pixel based classification approaches are limited in quantifying the land cover types in these environments, since these methods assign one single class for each pixel (Jensen 2014), not accounting for the mixing factor. Simple SMA address this problem by providing subpixel fractional estimates of land cover classes (Jensen 2014), but only considers a single endmember for each land cover type for the analysis, not incorporating the natural spectral variability of endmembers. MESMA improves on this limitation by permitting the variation of the number and types of endmember on a per-pixel basis (Roberts et al. 1998).

The Multiple Endmember Spectral Mixture Analysis (MESMA)

MESMA has been evaluated for many uses and, today, this approach is by far the most widely used SMA technique (Somers et al. 2011). This methodology has been 
successfully tested in natural (Fernández-Manso, Quintano and Roberts 2012), urban (Wu, Deng and Jia 2014), rural (Nogueira et al. 2015) and even in extraterrestrial environments (Combe et al. 2008).

Exploration of MESMA techniques suggested the potential robustness of such an approach back in the late 1990s (Roberts et al. 1998). This study took place in the Santa Monica Mountains and the aim of the research was to examine the use of MESMA for mapping chaparral in the mentioned area. The authors were able to map sixteen classes of vegetation in the region. Although the obtained results were not validated in the field, the authors conclude that MESMA provides a better discrimination between vegetation types and suggested that regionally specific spectral libraries represented a fruitful direction for further research.

Somers et al. (2011) summarize the available methods and results of the application of SMA and states five basic principles to mitigate endmember variability: the use of multiple endmembers for each component in an iterative mixture analysis cycle; the selection of a subset of stable spectral features; the spectral weighting of bands; spectral signal transformations; and the use of radiative transfer models in a mixture analysis. Covering a wide range of SMA research, the study highlights good practices to be applied in SMA procedures. The authors emphasize that although SMA has been proven effective in obtaining physically meaningful abundance data, the fractional estimate accuracies provided by this method are prone to residual spectral error. The use of fixed endmember spectra, as in SMA, implies that variation in endmembers spectral signatures, caused by spatial and temporal variability in the condition of scene components and differential illumination conditions, is not accounted by this methodology. In an attempt 
to reduce the errors related to endmember variability, MESMA permits multiple endmembers for each component and, thereby, refutes the inherent fixed endmember restriction of SMA.

Powell et al. (2007) published an article about mapping urban land cover using MESMA in Manaus, Brazil, with Landsat Enhanced Thematic Mapper (ETM+) imagery. For this research, a specific regional spectral library was built to apply MESMA. The application of such methodology is justified by the fact that most urban land-use classes are not spectrally distinct. The results' accuracy was evaluated by comparing them with high resolution, geocoded images mosaicked from an aerial survey. The obtained results point a systematic over-estimation of the vegetation fraction in the reference data, occurring, mostly, in high shaded areas. Despite the observed discrepancies, the authors consider that the used techniques adequately characterized the diversity of materials that comprise land cover within a diverse urban area.

Using Resoursesat-1 LISS-III imagery, a study evaluates the ability MESMA to identify dissimilar graze conditions in an area inserted in São Paulo State, Brazil (Nogueira et al. 2015). Via field survey, the authors classified the pasture areas in three types: well-managed, moderately degraded and degraded. The in-situ data was used to validate the obtained results. The outcomes of this research show that MESMA was effective in differentiating the well-managed pasture from the other ones, which didn't present signifying dissimilarities to each other.

Developing a spatially constrained MESMA method, with which multiple endmembers for each class are automatically derived within a predefined neighborhood, Wu, Deng and Jia (2014) aim to quantify urban impervious surfaces in a subpixel level in 
Columbus, Ohio. Using Landsat ETM+ imagery as input data, and black and white digital orthophotographs for validation, the researchers concluded that MESMA is able to provide adequate results for mapping fractional urban impervious surface distribution. The obtained results suggest that spatially constrained MESMA is able to yield adequate estimates for their study area.

A research assessing land cover change and anthropogenic disturbance in wetlands applying spectral mixture analysis (SMA), using Landsat Thematic Mapper (TM) scenes from 1984 to 2010, aims to determine if SMA applied to temporal multispectral data can be used to identify and monitor the mentioned phenomena in and around wetlands (Robertson, King and Davies 2015). The study took place in eastern Ontario region, Canada, where wetlands are common. The results were validated both by comparison with field data and through interviews with local experts. In conclusion, the authors consider that the SMA application is successful but, also, emphasizes that the results could be refined by implementing MESMA instead.

The work of Fernández-Manso, Quintano and Roberts (2012) examines three areas of surface coal extraction around the world (Spain, United States of America and Australia), using MESMA applied to Landsat TM data. The obtained results were validated using fine resolution orthophotographs as reference data and showed a significant improvement in the accuracy of detection of affected areas when compared with SMA and NDVI. The outcomes lead to the authors concluding that the MESMAbased approach is effective in mapping surface coal mining active affected areas.

The concepts of MESMA are not only used in research about Earth's surface. Using Multiple-Endmember Linear Spectral Unmixing Model (MELSIUM), a modification of 
MESMA, Combe et al. (2008), investigate the mineralogical composition of the Martian surface. For this research, the scientists used a spectral library composed of 24 spectra of minerals, covering the mineral families that might be found on the surface of Mars. The obtained results show that the application of MELSIUM provides good first order results in a variety of mineralogical contexts, and, therefore, can be confidently used on a wider scale to analyze the surface of the Red Planet.

The vast literature about MESMA applied to multispectral imagery demonstrates the relevance of the subject. Despite that, it is still necessary to proceed with further investigation on the matter, since the MESMA potentialities are still to be totally comprehended. 


\section{STUDY AREA}

Measuring 134 square kilometers, the study area is the Mayuni Conservancy, a smaller, bounded communal area just east of the Kwando River in the Zambezi Region of Namibia. The Kwando River flood plain, located along the western border of Mayuni Conservancy, present a broad soil moisture gradient and increased saturation in water pixels, creating difficulties in selecting endmembers of interest. Thus, the plain was excluded from the analysis in order to minimize spectral confusion during the endmember selection process.

The Mayuni Conservancy is located inside the Mudumu North Complex, a joint management area that embraces state and community conservation initiatives. Covering approximately 3,400 square kilometers, the complex is formed of a cluster of resource management areas and was established with the objective of managing the area's fauna and flora by guiding the development of tourism and natural resource use for social, cultural and economic benefits (NACSO 2012). The Mudumu North Complex is located in northeast Namibia, bordered by Zambia and Angola to the north and Botswana to the south and is a multifunctional landscape that includes protected areas and communal lands. The dominant land uses are smallholder agriculture in nutrient-poor, communal areas and livestock farming. The ecologically diverse savanna is represented by a gradient of tree to grass cover (Campos-Bescós et al. 2013).

The study area also falls centrally within the Kavango-Zambezi Trans-Frontier Conservation Area (KAZA), a vast ecosystem sprawling across Namibia, Zambia, 
Botswana, Angola and Zimbabwe (Shapiro et al. 2015). Being the world's largest transfrontier conservation area, KAZA has been designed to enhance the region's international profile and stimulate the eco-tourism industry centered on its spectacular natural attractions (Scovronick, Gordon and Turpie 2007). Another very relevant ecological characteristic of the area is that it acts as a seasonal migration corridor for wildlife moving across political boundaries (Naidoo et al. 2012). Due to these characteristics, there is no doubt that the study area is relevant under an environmental and development perspective, being worthy of research about methodologies aiming to more accurately quantify the land cover/use that takes place in the region. Figure 1 below shows the study area relative to the larger KAZA region.
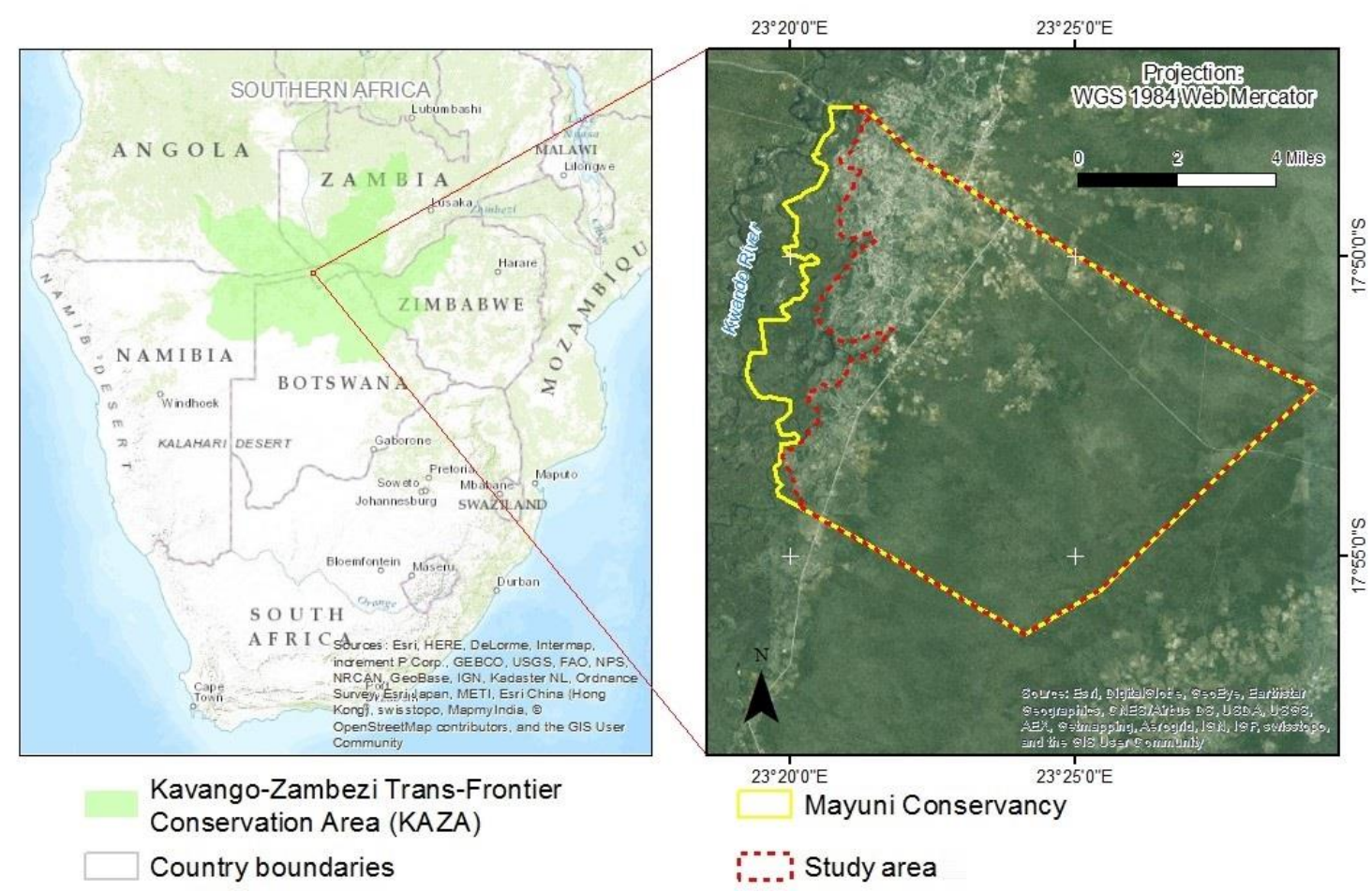

Figure 1. Study area location. 


\section{MATERIALS AND METHODS}

\section{$\underline{\text { Data }}$}

The Landsat platforms have been operational since 1972 and includes the currently working Landsat 8 satellite. This platform carries the Operational Land Imager (OLI) multispectral sensor. Landsat data has been extensively used to assess southern Africa's savanna land cover (Tucker, Townshend and Goff 1985; Palmer and van Rooyen 1998; Dube and Pickup 2001; Scanlon et al. 2002; Munyati and Ratshibvumo 2011) and as input data for application of MESMA (Myint and Okin 2009; Somers et al. 2010; Michishita, Gong and Xu 2012; Mishra, Crews and Okin 2014; Wu, Deng and Jia 2014). The data used for analysis in this study is a mosaic of orthorectified Landsat 8 OLI scenes. Prior to the mosaicking, each scene was atmospherically corrected by the Fast Line-of-sight Atmospheric Analysis of Spectral Hypercubes (FLAASH) algorithm (White et al. 2007). The resulting reflectance image was then subset to the study area perimeter. The 2014 imagery was acquired at the beginning of the dry season, during the month of May, which permitted the acquisition of cloud-free images, thus optimizing the amount of actual land-cover detected. Originally downloaded from GLOVIS (USGS) (http://golvis.usgs.gov), the OLI data includes the following specifications listed in Table 1. 


\section{Table 1}

Landsat 8 OLI sensor specifications (USGS 2015).

\begin{tabular}{|c|c|c|c|}
\hline \multirow[b]{5}{*}{ Band \# } & \multicolumn{2}{|c|}{ Satellite: Landsat 8} & \multirow[b]{5}{*}{ Spatial Resolution } \\
\hline & \multirow{2}{*}{\multicolumn{2}{|c|}{ Sensor: Operational Land Imager (OLI) }} & \\
\hline & & & \\
\hline & \multicolumn{2}{|c|}{ Number of bands: 9} & \\
\hline & Alias & Bandwidth $(\mu \mathrm{m})$ & \\
\hline 1 & Coastal aerosol & $0.43-0.45$ & 30 meters \\
\hline 2 & Blue & $0.45-0.51$ & 30 meters \\
\hline 3 & Green & $0.53-0.59$ & 30 meters \\
\hline 4 & Red & $0.64-0.67$ & 30 meters \\
\hline 5 & Near Infrared (NIR) & $0.85-0.88$ & 30 meters \\
\hline 6 & Short Wave Infrared 1 (SWIR 1) & $1.57-1.65$ & 30 meters \\
\hline 7 & Short Wave Infrared 2 (SWIR 2) & $2.11-2.29$ & 30 meters \\
\hline 8 & Panchromatic & $0.50-0.68$ & 15 meters \\
\hline 9 & Cirrus & $1.36-1.38$ & 30 meters \\
\hline
\end{tabular}

The bands considered in this study were: 2 (blue), 3 (green), 4 (red), 5 (NIR), 6 (SWIR 1) and 7 (SWIR 2). Bands 1 and 9 were not used because they were designed to detect phenomena occurring in the atmosphere instead of Earth's surface. Band 8 (Panchromatic) was not used. This band encompasses a wide range of wavelengths and it is used for spatial resolution enhancement only, and was deemed not useful to spectral characterization of features in the current approach. 
In addition, the area's NDVI (Normalized Difference Vegetation Index) and NDBI (Normalized Difference Built-up Index) were calculated. While NDVI provides valuable information about vegetation biomass, NDBI is useful to assess the spatial distribution of built-up and barren areas (Jensen 2014). Since the study area is rural, this second index was chosen primarily for information about bare soil. Also, the difference between the indices (NDVI-NDBI) was calculated, in order to generate a layer that emphasizes the difference between barren and vegetated areas even more (Fasial and Shaker 2014). The formulas for NDVI and NDBI are described by equations (1) and (2), respectively.

$$
\mathrm{NDVI}=\frac{\rho_{\text {nir }}-\rho_{\text {red }}}{\rho_{\text {nir }}+\rho_{\text {red }}}
$$

where $\rho_{\text {nir }}$ and $\rho_{\text {red }}$ are the reflectance values in the NIR and red bands, respectively (Jensen 2014).

$$
\mathrm{NDBI}=\frac{\rho_{\text {swir1 }}-\rho_{\text {nir }}}{\rho_{\text {swir2 }}+\rho_{\text {nir }}}
$$

where $\rho_{\text {swirl }}$ and $\rho_{\text {swir2 }}$ are, respectively, the reflectance values for the SWIR 1 and SWIR 2 bands (Jensen 2014).

NDVI and NDBI values fluctuate between 1 and -1, reflecting, respectively the vegetation productivity and level of land bareness in a directly proportional manner. In turn, the image's reflectance values vary from 0 to 7,141 , due to the FLAASH calibration procedure. Therefore, the indices had to be rescaled according to the reflectance values. To do so, the NDVI and NDBI values were multiplied by a factor of 10,000 . The data was then layer stacked in ENVI Classic software, in a 9 layers arrangement, as described in Table 2.

\section{Table 2}

$\underline{\text { Landsat } 8 \text { layered bands and indexes arrangement. }}$ 


\begin{tabular}{cc}
\hline Layer number & Layer name \\
\hline 1 & Landsat 8 OLI band 2 - Blue \\
2 & Landsat 8 OLI band 3 - Green \\
3 & Landsat 8 OLI band 4 - Red \\
4 & Landsat 8 OLI band 6 - SWIR 1 \\
5 & Landsat 8 OLI band - SWIR 2 \\
6 & Rescaled NDVI \\
7 & Rescaled NDBI \\
8 & Rescaled NDVI - NDBI
\end{tabular}

Also, high spatial resolution imagery from the Worldview-2 satellite was used as ancillary data. Specifically, the panchromatic band, which encompasses wavelengths between 450 and $800 \mathrm{~nm}$, with a pixel size of 50 by $50 \mathrm{~cm}$ provided information to assist with the endmember selection process and for validation of MESMA results.

\section{The spectral mixing model}

The energy recorded by a remote sensing detector is a function of the amount of energy reflected or emitted by the materials within the Instantaneous-Field-Of-View (IFOV). Spectral Mixture Analysis (SMA) provides means to determine and report the actual proportion (or abundance) of pure endmembers materials within the pixel (Jensen 2014). Endmember spectra represent a target class or cover type believed to be present at the subpixel level and can be collected from reference materials in a laboratory setting, measured in the field, simulated with radiative transfer modeling (Roth, Dennison and 
Roberts 2012) or even identified in the data to be unmixed with the support of high spatial resolution data (Lu and Weng 2004).

The understanding of the spectral mixing process is fundamental towards a more complex process knowns as Multiple Endmember Spectral Mixture Analysis (MESMA). The spectral mixing occurs according to what is described by equation (3):

$$
\rho_{\lambda}^{\prime}=\sum_{\mathrm{i}=1}^{\mathrm{n}}\left(\rho_{i \lambda} \times f_{i}\right)+\varepsilon_{\lambda}
$$

where $\rho_{\lambda}$ is the reflectance at wavelength, $\lambda$; $\rho_{i \lambda}$ is the spectral reflectance of endmember $i$, and $f_{i}$ is the fractional cover of endmember $i$. The total number of endmembers is expressed by $n$ and the model error is $\varepsilon_{\lambda}$ (Jensen 2014). By allowing the types and numbers of endmembers to vary, MESMA performs the best fractional breakdown possible per pixel (Roberts et al. 1998). The concept of spectral unmixing for an individual pixel and the application of equation (3) are depicted in Figure 2.

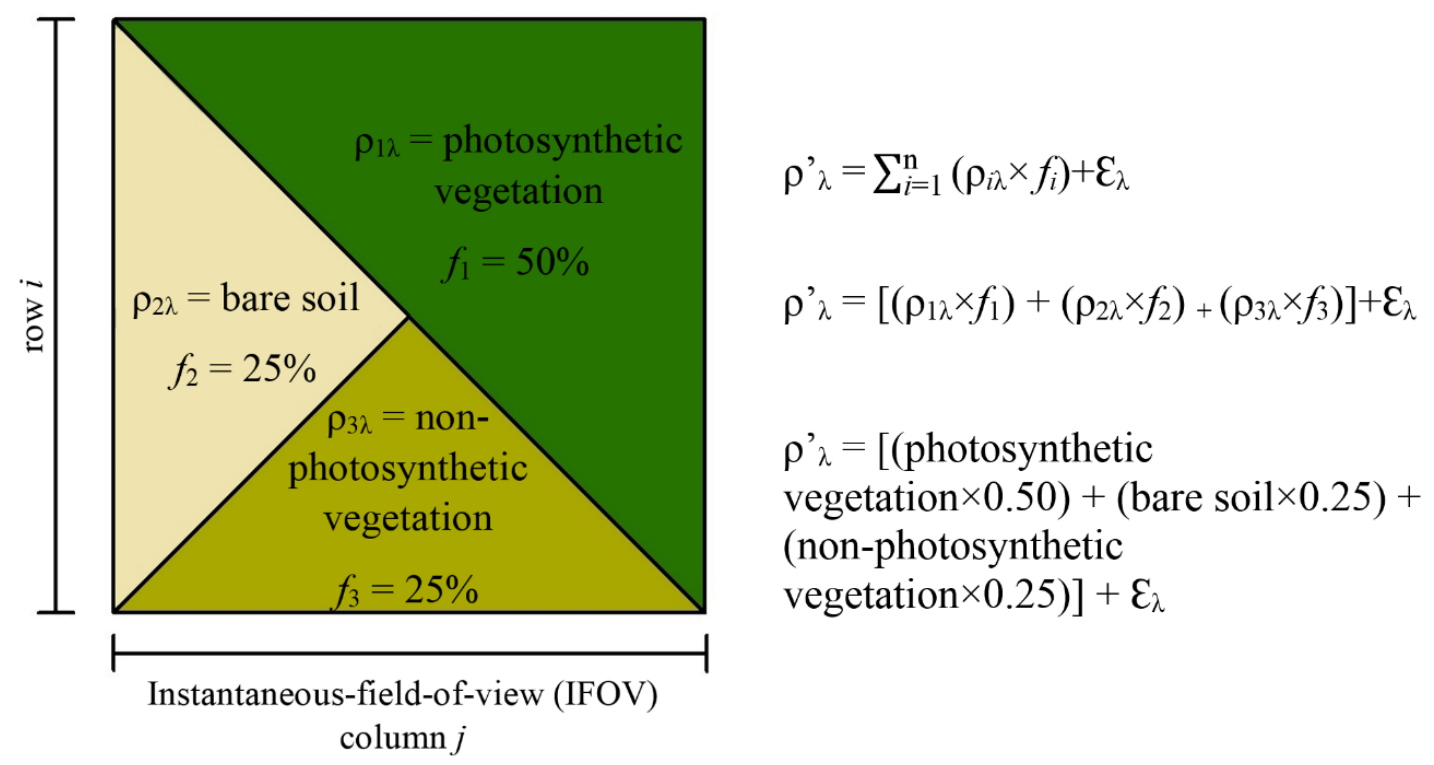

Figure 2. Linear spectral mixing model for a single pixel and application of SMA equation (Jensen 2014, adapted) 


\section{Endmember selection}

The selection of adequate endmembers is essential for any SMA method. Even though laboratory measurements of pure endmembers are considered to be the optimal approach to subpixel classifiers (Wu and Murray 2003) selecting endmembers from homogeneous land covers from satellite images is a viable alternative. Among the advantages of image derived endmembers, two deserve to be mentioned: firstly, endmembers selected from imagery contain the same systematic errors due to atmospheric correction as the image to be unmixed (Settle and Drake 1993); secondly, image endmembers represent responses from the selected material at the same scale as the original image (Myint and Okin 2009). So, due to these properties, the selection of endmembers from the image itself was used for analysis.

Endmembers are regarded as the extremes in the triangles in a scatterplot of the digital values of two bands as depicted in Figure 3(Lu and Weng 2004). In this sense, SMA works in a different manner than a minimum distance classifier, which uses the mean vectors of each class for assessing land cover instead of extreme values (Kruse and Perry 2013). 


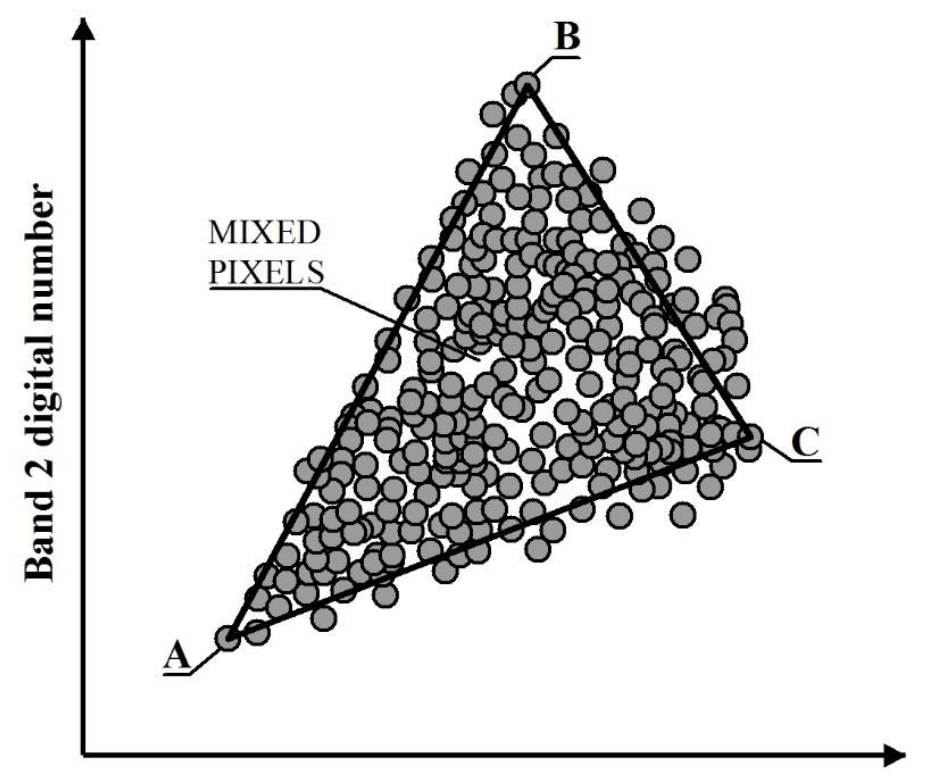

Band 1 digital number

Figure 3. Scatterplot of hypothetical bands 1 and 2, showing endmembers A, B and C. However, it is well recognized that adjacent bands are highly correlated (Lu and Weng 2004). This correlation may complicate the endmembers identification process, since the scatterplot of highly correlated bands assumes a nearly linear shape, instead of a polygonal one. In order to better identify the image's endmembers it is necessary to reduce this correlation, which can be done by Principal Component Analysis (PCA) and Minimum Noise Fraction (MNF) transformation (Jensen 2014).

PCA is a technique that transforms the original remotely sensed data into a considerably smaller and easier to interpret set of uncorrelated variables that represent most of the information present in the original dataset. In such a context, principal components are extracted from the original data in a manner that the first principal component accounts for the maximum proportion of the original data's variance, and subsequent orthogonal components account for the maximum proportion of the remaining 
variance (Jensen 2014). The concept of PCA in a two-dimensional scatterplot of bands from remotely sensed data is illustrated in Figure 4.

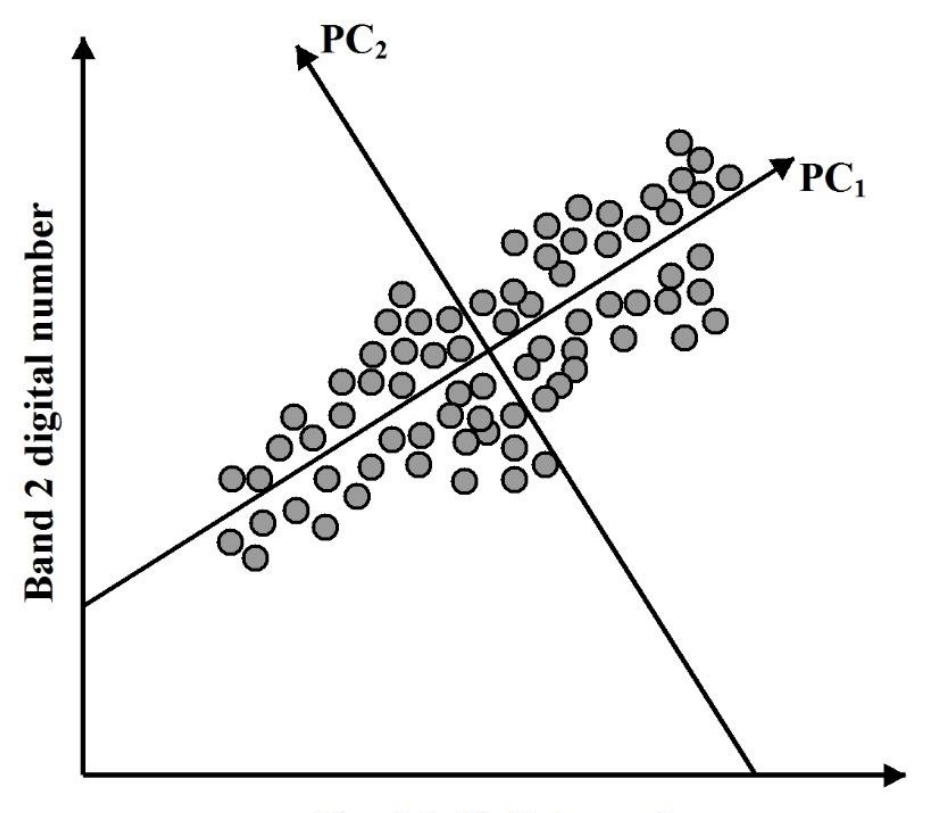

Band 1 digital number

Figure 4. Representation of the spatial relationship between the first two principal components in a scatterplot of two hypothetical bands, where $\mathrm{PC}_{1}$ is the principal component 1 and $\mathrm{PC}_{2}$ is the principal component 2.

The Minimum Noise Fraction (MNF) rotation was performed in the Landsat image to be unmixed in order to locate optimal endmembers. MNF is a consecutive series of PCAs performed over the same data, and one of the most common transformations used to reduce correlation between bands of multispectral and hyperspectral remotely sensed data (Jensen 2014). The MNF transformation is processed in two steps: firstly, it decorrelates and rescales the data's noise, producing transformed data in which the noise has unit variance and no band-to-band correlations; secondly, MNF implements a standard PCA of the noise-whitened data. So, the MNF separates the noise from the 
actual data by using only its coherent portions, improving the quality of fractional images (Lu and Weng 2004). The processing of MNF and subsequent steps were done by using the ENVI Spectral Hourglass Wizard toolset.

The first step of MNF processing was to select the layer stack in Table 2 as input data, considering the full scene as the spatial subset and all 9 bands as the spectral subset. Also, all values outside the study area were masked out, and thus, were not considered in the data processing. The obtained MNF's outputs are ranked according to the amount of variance with the most variation represented by the first component (i.e. band), provided by a numeric variance measure. In this sense, the majority of the variance occurs in the first band and decreases with increasing band number. So the first few bands contain valuable information while the last ones are noise dominated. Therefore, the bands containing mostly noise were not used in the subsequent processes. (Green et al. 2013). The first 6 bands of MNF were selected to be used for the endmember selection since they presented the highest dimensionality among the MNF outputs. Figures 5 and 6 show, respectively, the plot of the obtained eigenvalues and the MNF output bands.

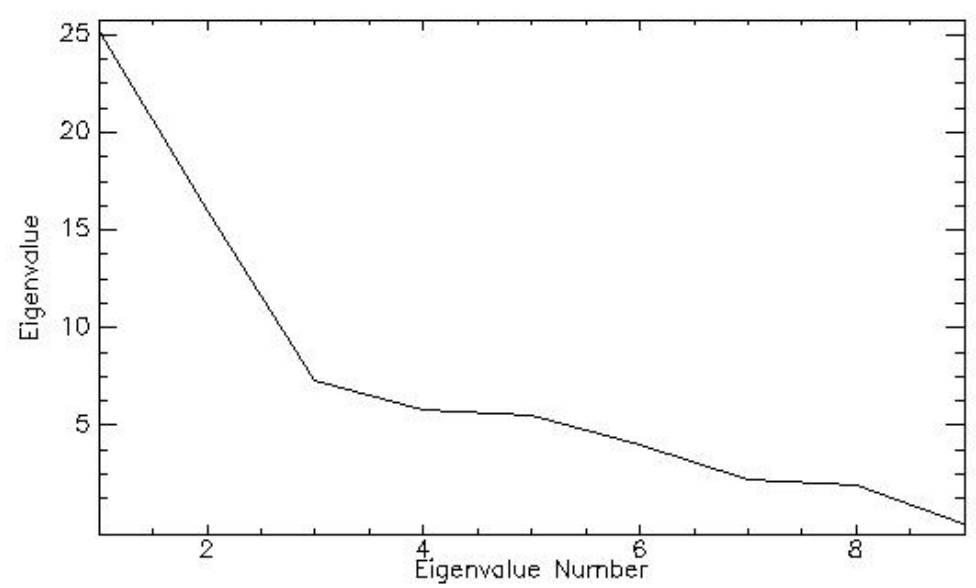

Figure 5. MNF eigenvalues plot, where the vertical axis shows the eigenvalues and the horizontal axis show the eigenvalue number, which corresponds to MNF bands order. 
a)

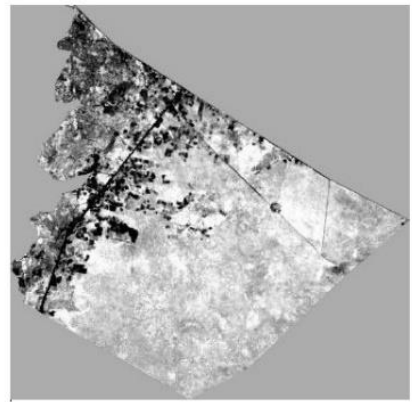

d)

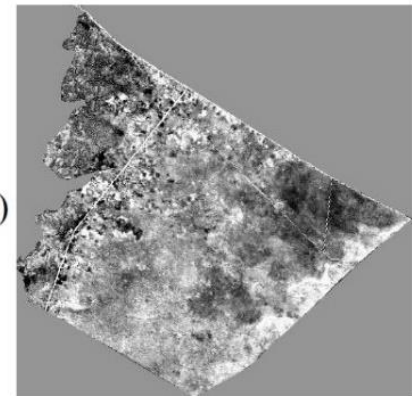

g)

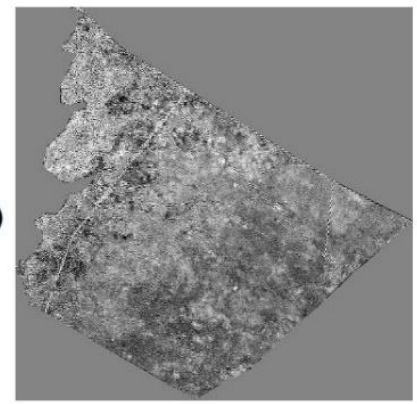

b)

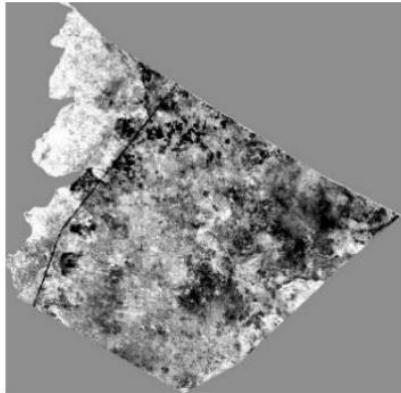

e)

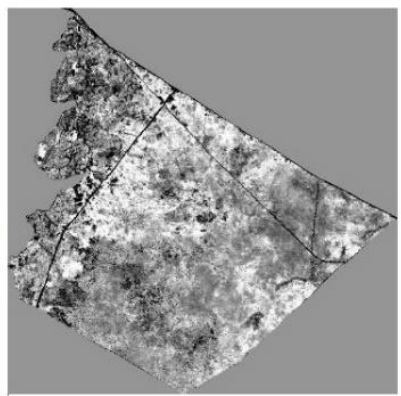

h)

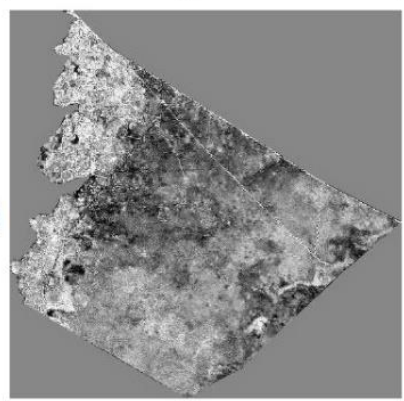

c)

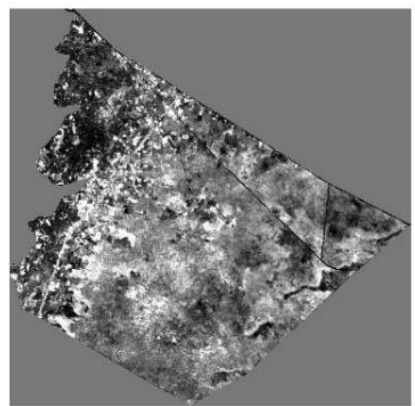

f)

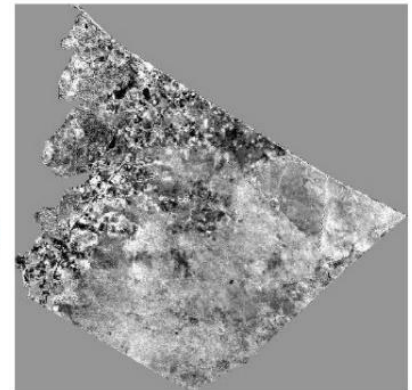

i)

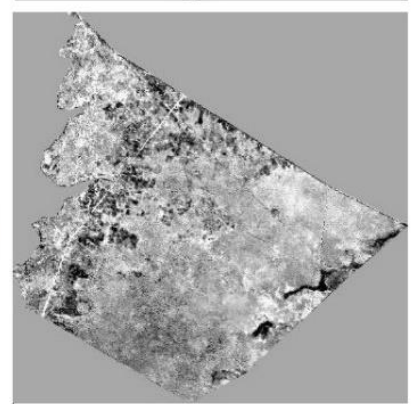

Figure 6. MNF bands, where a) correspond to band 1, b) to band 2, and so on.

The next step was to calculate the Pixel Purity Index (PPI). The PPI input data is projected onto a randomly oriented vector passing through the mean of the data cloud. This method calculates a score based on the number of times each pixel is found to occupy a near-vertex position, in relation to the vector, through the repeated projections of the n-dimensional data. The output scores help to identify image endmembers since those pixels that hold pure spectra often display high PPI scores (Myint and Okin 2009). The PPI was calculated with 20,000 iterations and a threshold value of 2.50 . Then, the 10,000 PPI pixels with the highest values were plot in the n-D Visualizer (Figure 7). 


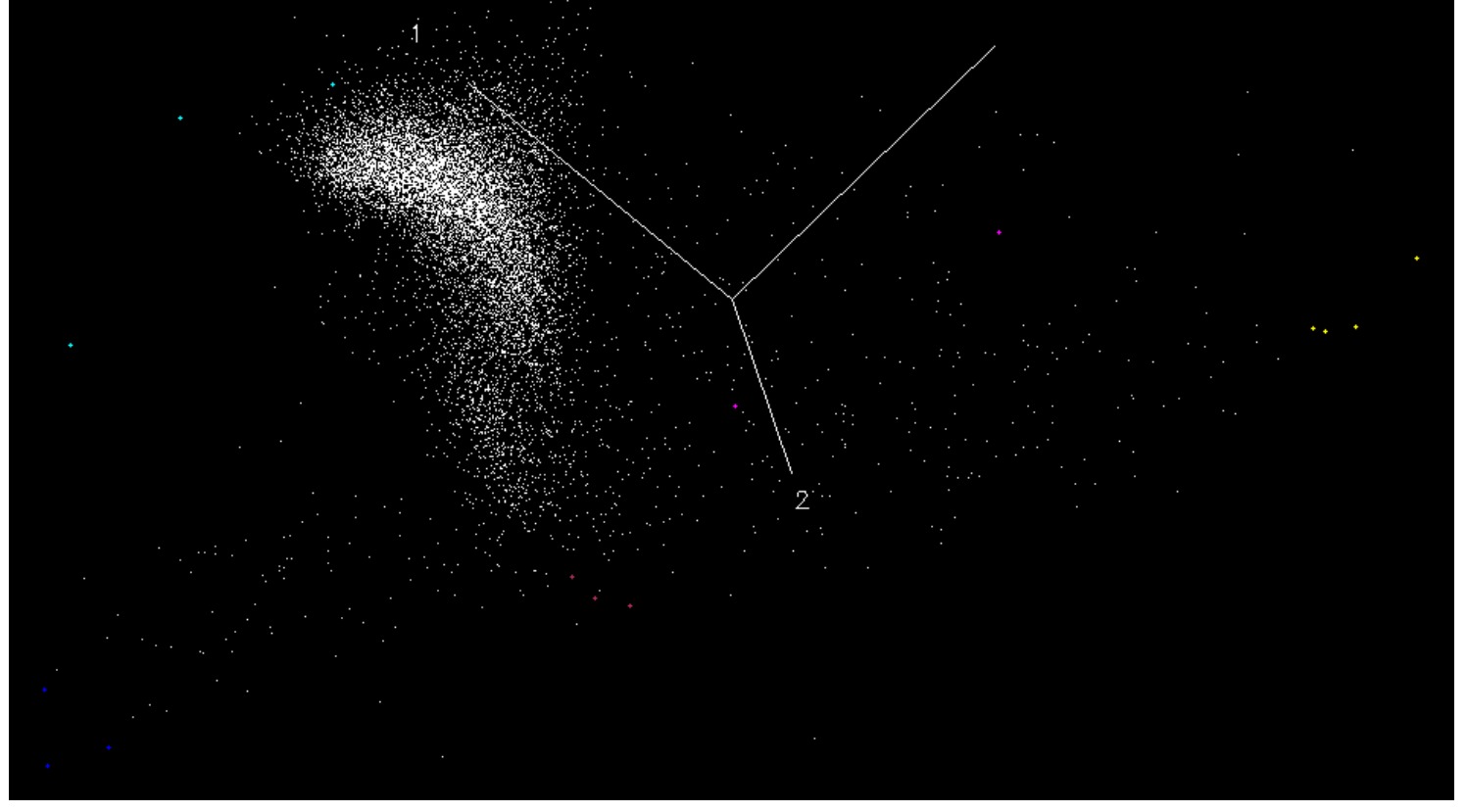

Figure 7. N-dimensional visualizer, where the dots represent the pixels from PPI calculation and the axis correspond to the first 3 MNF bands.

The axes in the n-dimensional visualizer can be set to represent any of the 6 significant MNF bands. Similarly to what occurred in the before mentioned twodimensional scatterplot, the pixels at the extremities of the n-dimensional visualizer are expected to be the purest ones. The extreme pixels were selected by rotating the scatterplot and observing which pixels fell in extreme positions in successive band combinations. The selected pixels are depicted by the colored dots in the n-dimensional visualizer and represent candidate endmembers (Figure 7). Then, those pixels were exported to Regions of Interest (ROIs) files in order to identify their spatial location on the image to be unmixed. The generation of the ROIs was the last procedure performed using the ENVI Spectral Hourglass Wizard toolset. 
The next step was to identify which endmember candidates were pure pixels. To do so, the ROIs were overlaid on the Landsat data, which was geographically linked to the Worldview-2 image. In the Worldview-2 panchromatic image, it is possible to visually identify woodlands/shrublands (PV), grasslands (NPV) and bare soil (B), (Figure 8). Then each ROI was visited to check if they were, in fact, pure pixels (endmembers). Since the images were geographically linked, it was possible to identify the full content of the Landsat 8 OLI pixels in the Worldview-2 image (Figure 9).

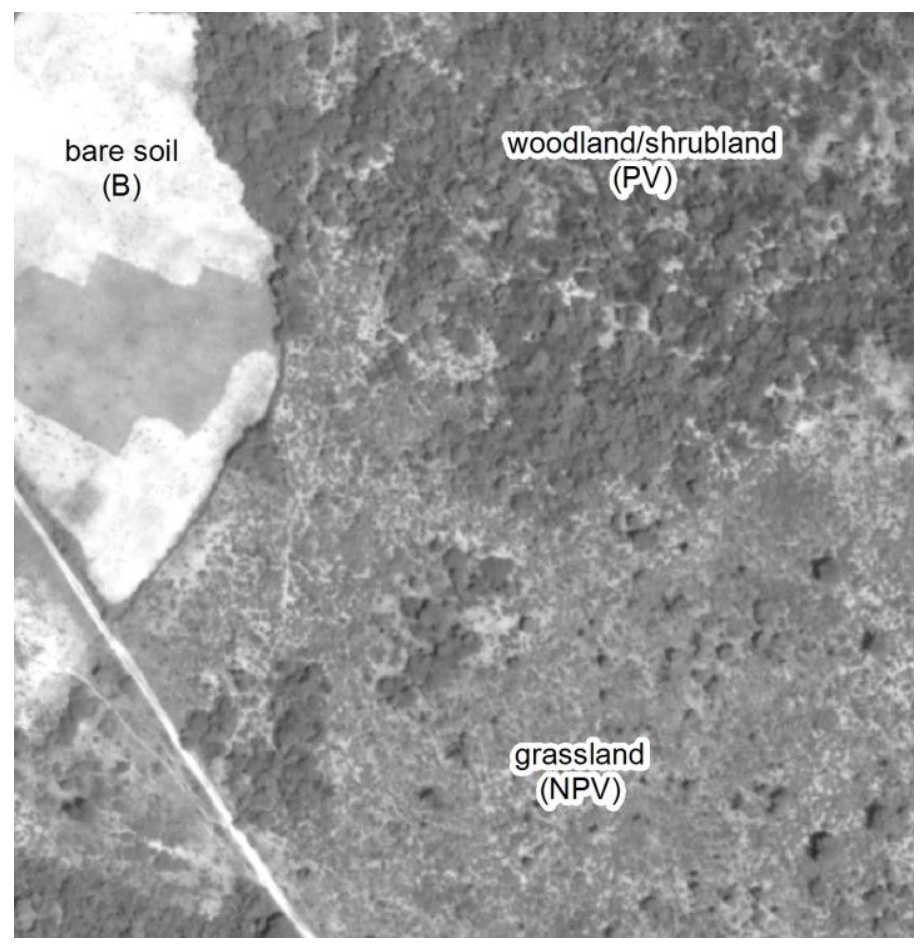

Figure 8. Worldview-2 image fragment showing the aspects of woodland/shrubland (PV), grassland (NPV) and bare soil (B). 

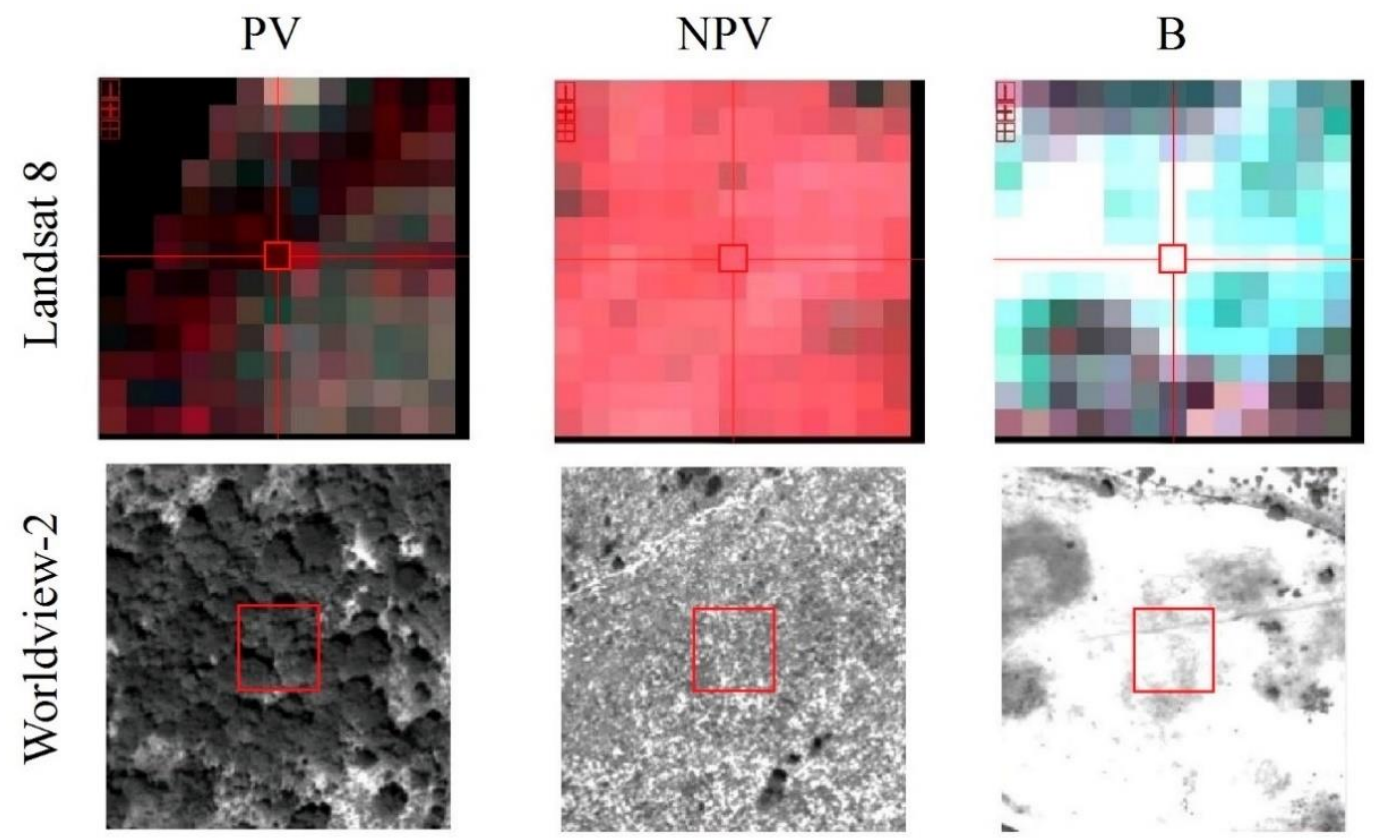

Figure 9. Landsat 8 and Worldview-2 images geographically linked together. The red squares in the Worldview-2 images correspond to the content of the pixel in the crosshair on the Landsat 8 counterpart.

Through this process, spectral signatures of purest Landsat pixels were identified as the endmembers for use in the MESMA approach. A total of 10 endmembers were identified: 3 for PV, 3 for NPV and 4 for B.

\section{MESMA processing}

The MESMA processing was done using VIPER Tools open software (www.vipertools.org) in ENVI Classic 5.3. This software package provides a collection of processing tools for multiband passive optical remote sensing data, including hyperspectral and multispectral imagery. The main components of VIPER Tools were designed for creation and management of spectral libraries, selection of optimal endmembers for SMA and calculation and interpretation of SMA and MESMA (Roberts, Halligan and Dennison 2007). 
The first step was to merge the obtained endmembers together in spectral libraries. One spectral library for each endmember type was created, resulting in one PV spectral library containing 3 endmembers, one NPV spectral library containing 3 endmembers, and one B library containing 4 endmembers. Figure 10 shows these spectral libraries.
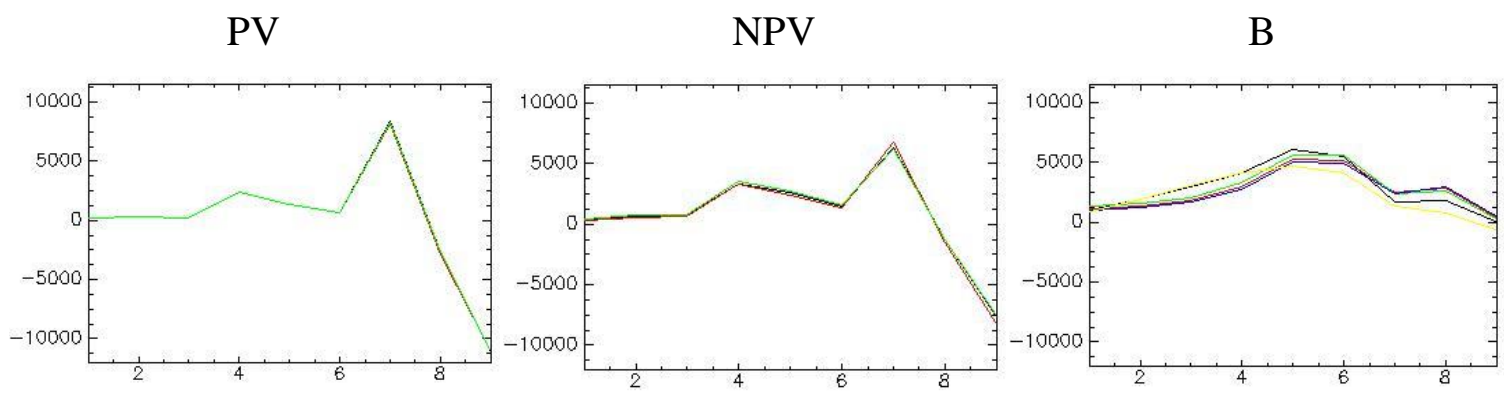

Figure 10. Spectral libraries showing the spectral signatures of PV, NPV and B endmembers.

Two types of input data were used to run MESMA. The first one is the Landsat 8 OLI image to be unmixed. The image's scale factor was defined as 10,000 , since it is a reflectance image. The second type of input data is composed of the spectral libraries representing endmembers. Also, a fourth shade endmember was taken into account. In this case it was a preset photometric endmember, which considers shade as zero reflectance values (Roberts, Halligan and Dennison 2007). With the 11 endmembers (10 collected from the image representing land cover and a photometric one representing shade), a total number of 45 models were considered for the MESMA processing. The fractions' constraints were set to a minimum of 0 and a maximum of 1 , not allowing negative values or values bigger than one unit for endmember fractions.

In addition to fractional images, the Root Mean Squared Error (RMSE) of the best candidate model is calculated. This statistical measure indicates the model fit for each pixel, and it is calculated by the equation (4). 


$$
\mathrm{RMSE}=\sqrt{\sum_{\mathrm{k}=1}^{\lambda}\left(\varepsilon_{\mathrm{i} \lambda}\right)^{2} / \mathrm{N}}
$$

where $\varepsilon_{\mathrm{i} \lambda}$ is the wavelength and $\mathrm{N}$ is the number of reference endmembers (Roberts et al. 1997). In this sense, the magnitude of the RMSE between the modeled and observed reflectances provides a quantitative measurement of how well the estimated fractions and endmembers can reproduce the observed reflectance (Small 2004).

To validate the MESMA, its results were compared to the content observed in the Worldview-2 image. Then, scatterplots considering observed and calculated values were created in order to assess the relationships between these values. These scatterplots were generated for each one of the endmembers and provide a preliminary visualization of the correlation between the involved datasets. Also, the data depicted in these graphics was used to assess MESMA's accuracy in a measurable manner.

In order to quantify the results' accuracy, the Pearson's correlation coefficient (r) was calculated taking into account the data contained in the above mentioned scatterplots. This coefficient represents the ratio of the joint variation of two variables to the total variation of the entire dataset. In $r$ calculation, the numerator represents the extent to which an increase in one of the compared values affects the other in a proportional manner. In turn, the denominator represents the total variation in the dataset, calculated by multiplying the standard deviations of the two variables (Mitchel 2009). Therefore, $r$ is calculated according to equation (5).

$$
\mathrm{r}=\frac{\sum \mathrm{x}_{\mathrm{i} y \mathrm{i}}-\mathrm{n} \overline{\mathrm{x}} \overline{\mathrm{y}}}{(\mathrm{n}-1) \mathrm{S}_{\mathrm{x}} \mathrm{S}_{\mathrm{y}}}
$$

where, $\mathrm{x}$ is the first variable, $\mathrm{y}$ is the second variable, $\mathrm{n}$ is the number of features, $\overline{\mathrm{x}}$ and $\overline{\mathrm{y}}$ are the variable's means, and $S_{x}$ and $S_{y}$ are the standard deviations of the variables. 
The values of $r$ vary between 1 (indicating a perfect direct relationship) and -1 (a perfect inverse relationship). A value of $r$ that approaches these values indicates that almost all of the variation in the dataset is accounted for by the covariance of the two analyzed variables. An r value near 0 indicates that the covariance in the two variables is negligible compared to the variation for the total dataset (Mitchel 2009). 


\section{RESULTS}

The MESMA was successfully applied to $92.9 \%$ of the study area. The unmapped areas are those where one or more spectral signature were not captured by the constraints specified in the study's methodology. The output of this analysis includes individual images that contain information about the proportion of endmembers for each pixel. For pixels where the current endmember parameters were successful, the obtained total proportions of PV, NPV and B were, respectively, 32.3\%, 32.0\% and 25.2\%. The shade fraction represents $10.6 \%$ of the analyzed landscape. Figure 11 highlights the B, NPV, PV composite, where black inside the study area are regions where MESMA failed to extract fractional values. The fractional percentage of each land cover of interest is highlighted in Figure 12, with the brighter pixels representing higher proportions of a given endmember and vice-versa. 


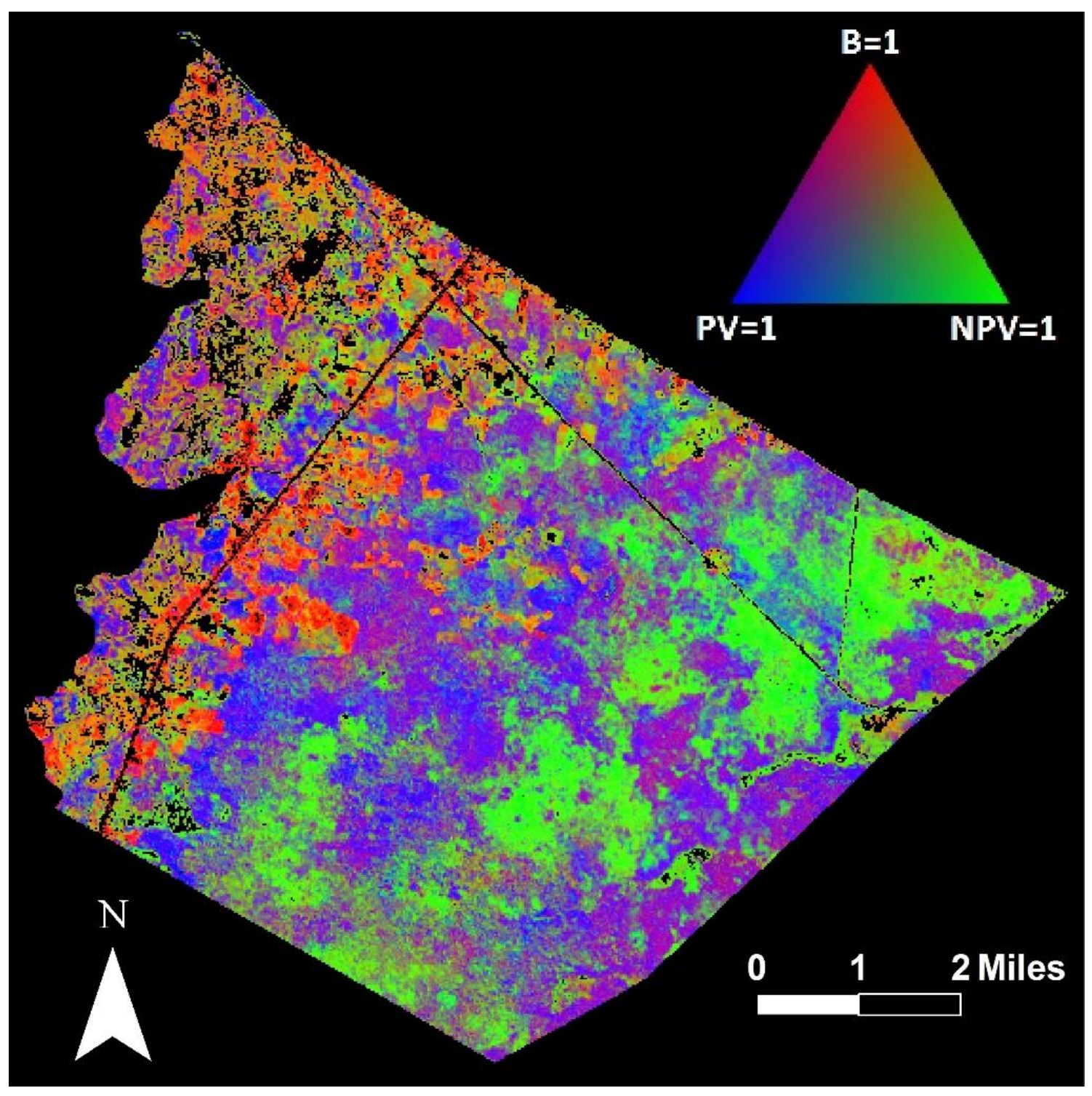

Figure 11. Resulting fraction image in a B, NPV,PV RGB composite. 

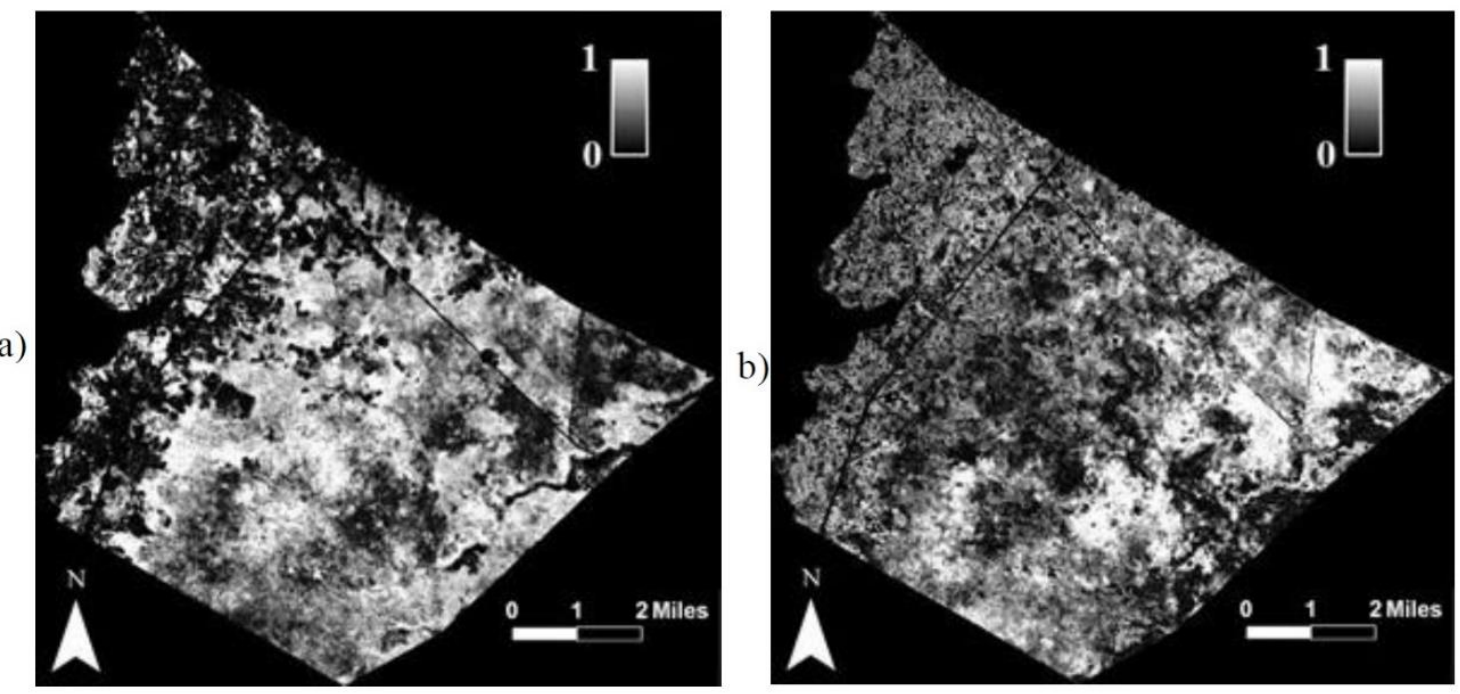

c)
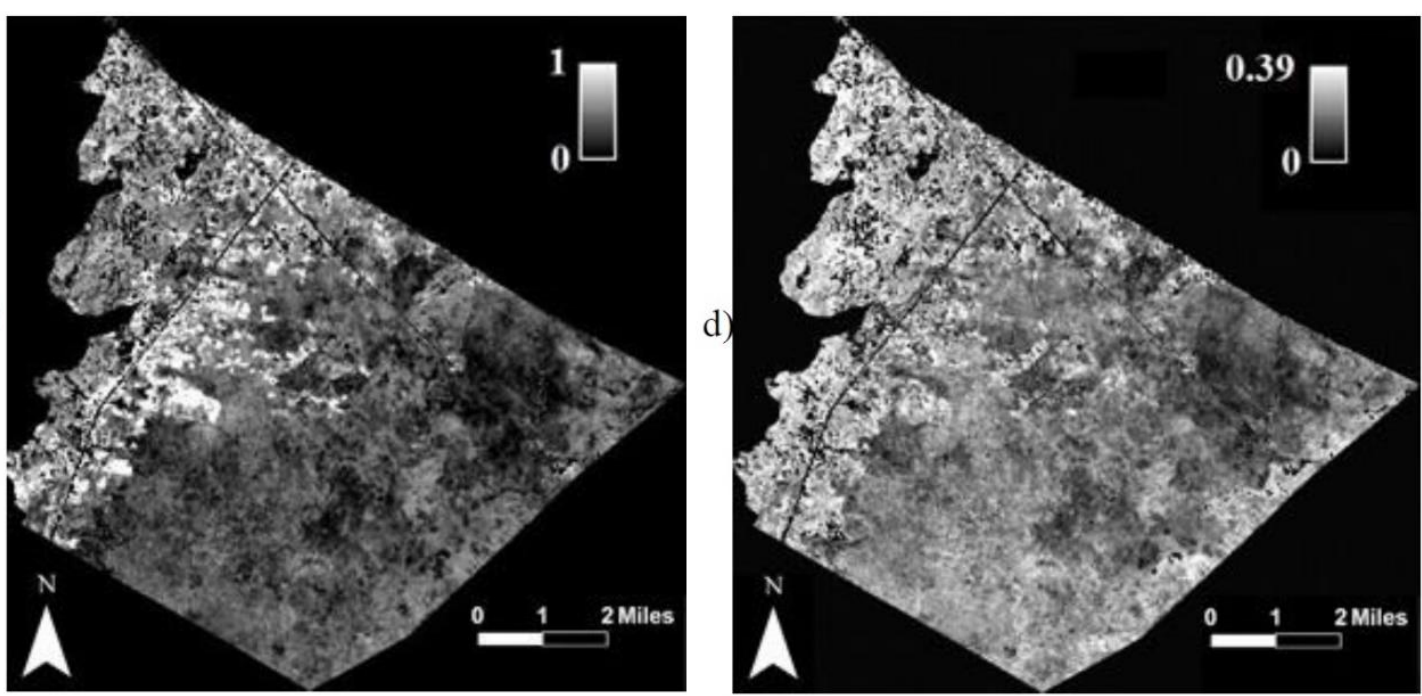

Figure 12. Individual fraction images obtained from MESMA, where a) represents PV; b), NPV; c), B; and d) shade.

\section{Accuracy Assessment}

Visually, the distribution of the results is coherent to what is observed in the high resolution Worldview-2 image. When the fractional images are overlaid on top of Worldview-2 data it is possible to notice that higher values of PV occur where shrubs and trees are the main type of land cover. The NPV correspond to those areas with predominant grass cover, as we can see in the eastern part of the study area. For the B 
fractional image there are brighter pixels in those areas where the vegetation was removed by anthropic activities. The distribution of the shade fraction is the most homogeneous of all, but presents some slightly high values in the western part of Mayuni, near the flood plain, and somewhat low values where the NPV fraction is higher.

A 2.2\% average RMSE was calculated for the study area output. The total range of the RMSE encompasses values between $0 \%$ and $9.4 \%$ throughout the image. The RMSE image is shown in Figure 13.

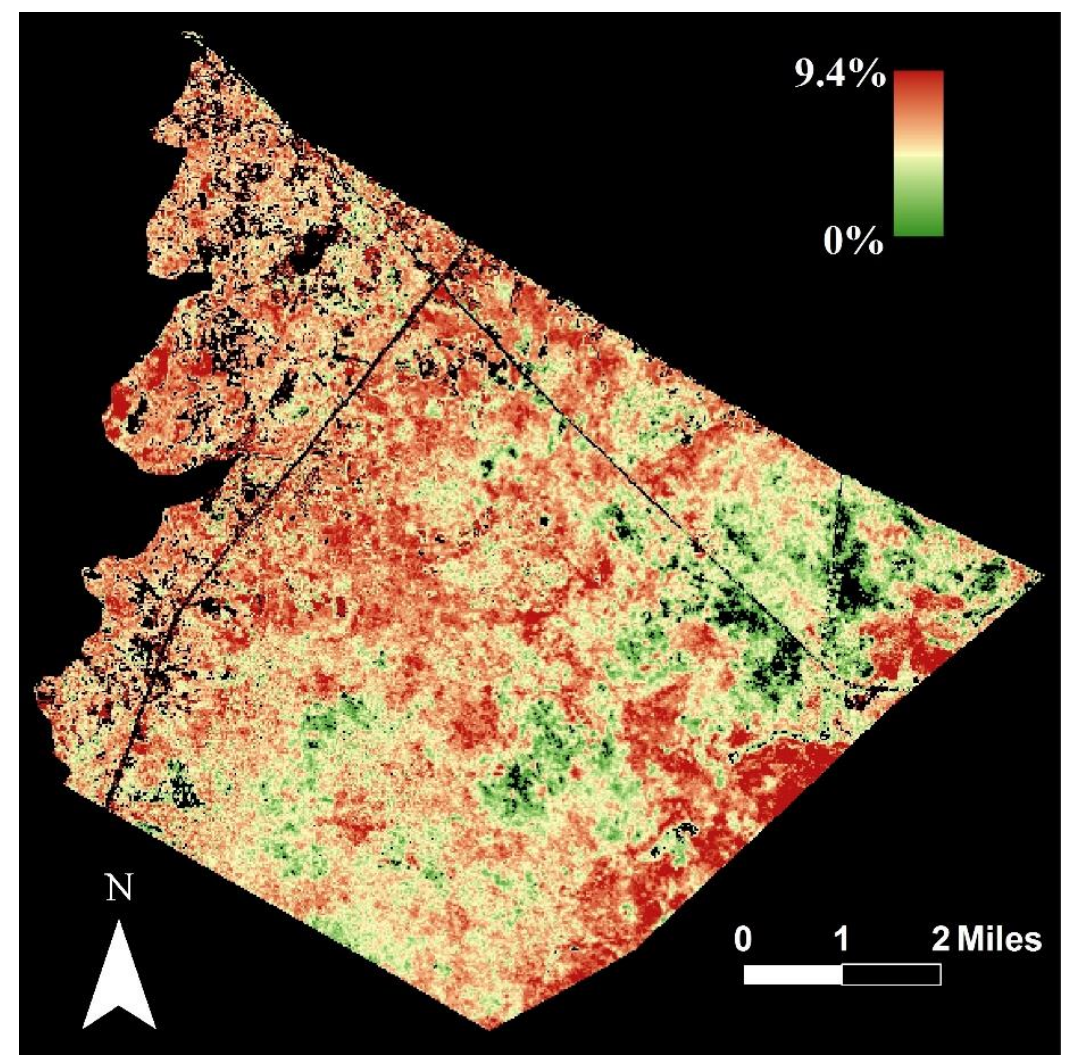

Figure 13. Image showing the RMSE distribution across the mapped area.

The obtained RMSE values were higher for PV areas, indicating that the PV fractional estimates are less consistent with the observed reflectance when compared to the other endmembers. In turn, lower RMSE values are associated with NPV, suggesting that the models used to map this land cover presented a better fit. 
To quantitatively examine the accuracy of the MESMA output, the fractional data was converted into a polygonal vector, with each pixel representing one square polygon of the vector. Then, 30 polygons were randomly selected. Inside each polygon, 20 random sample points were generated, totaling 600 points for the whole study area. The values PV, NPV, B or shade were attributed to each point according to the class they fell on the Worldview-2 imagery. Due to the number of points per pixel, the validation fractions obtained from the sample points vary in a 5\% basis. Figure 14 outlines the process of generating the 20 sample points inside one polygon plotted on the Worldview2 data.
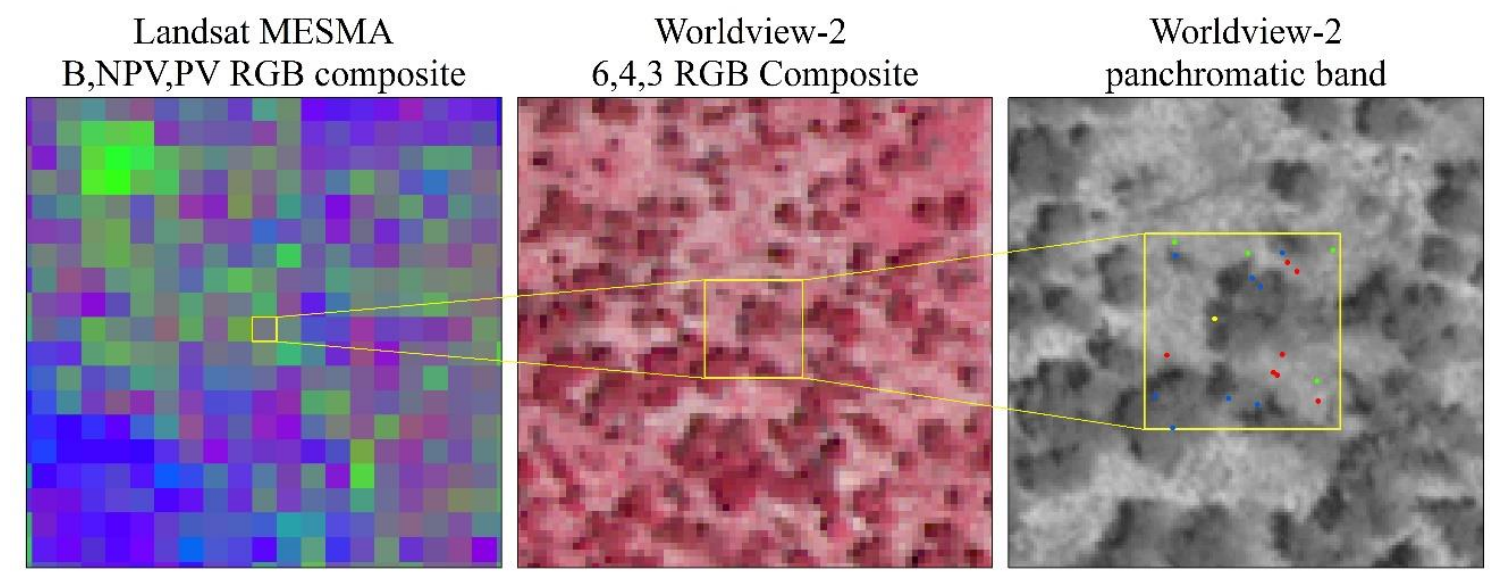

Figure 14. Sample points distributed inside an area that represents a single fractional image's pixel, where red, green, blue and yellow dots are B, NPV, PV and shade sample points, respectively.

After sample point creation, scatterplots for each endmember were generated to compare the MESMA outputs to the validation proportional values. Figure 15 depicts the above mentioned scatterplot for each endmember accounted in this study. 

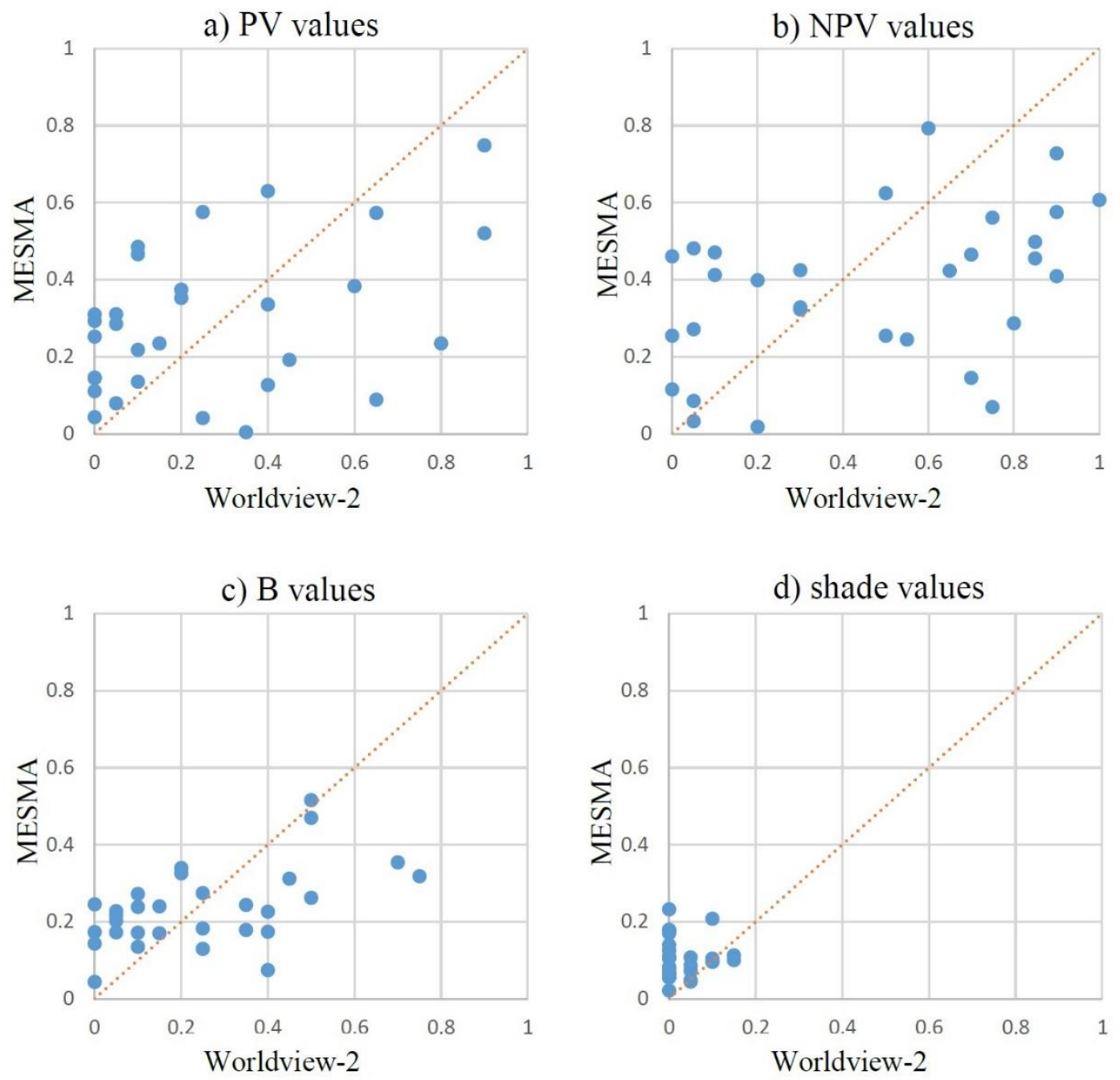

Figure 15. Scatterplots depicting the relationship between the results obtained with MESMA and those generated in the validation process, with 1:1 line as a reference of perfect positive correlation.

Results shown in Figure 15 indicate that the B fractions calculated by MESMA are underestimated when compared to the validation data. For the shade values, which are comprehensibly low for both datasets, MESMA presents values higher than those measured in the Worldview-2 image. The scatterplots representing vegetation are more dispersed than the others and, so, the visual analysis doesn't suggest a general and 
systematic estimation error. However, this dispersive characteristic is indicative of a lack of correlation between calculated and observed values.

The obtained $r$ values were 0.42 for PV, 0.43 for NPV, 0.52 for B and 0.06 for shade, indicating a moderate correlation for PV, NPV and B, and almost null for the shade fraction. These results suggest that MESMA was slightly more effective in estimating the proportion of bare soil on the landscape when compared to the estimates relative to vegetated areas. Also, the algorithm performed very poorly in estimating the shade fraction.

The obtained MAE values were 0.23 for PV, 0.27 for NPV, 0.15 for B and 0.08 for shade. Since in this study these values can vary from 0 to 1 , the MAEs calculated are relatively low, suggesting a reasonable proximity between the MESMA results and the data extracted from Worldview-2 data. For the shade fraction, the values are much lower, reaching a maximum of 0.39 , so the MAE value of 0.08 obtained for shade is relatively lower than the values obtained for the vegetated areas, but higher than those obtained for the bare soil regions. Although the calculated correlation is weaker than anticipated, its positive character indicates that MESMA successfully assesses, in some degree, the fractions of PV, NPV, B and shade in the study area. So, considering the complexity and heterogeneity of the landscape analyzed in this study, it is accurate to say that MESMA provided reasonable results. 


\section{DISCUSSION}

The results visually portray the proportions of PV, NPV and B in the study area, with patterns observed in the MESMA output associated to landscape patterns identified in the Worldview-2 data. The thesis' objective of obtaining fractional images by applying MESMA to Landsat 8 OLI data was accomplished. The analysis points out that the majority of the mapped area is vegetated and that the fractions of PV and NPV are almost equal (32.3\% and 32.0\%, respectively), followed by B (25.2\%). As expected, the shade fraction was low, corresponding to $10.6 \%$ in the analyzed landscape. The proportions are distributed in $92.9 \%$ of the study area, where MESMA was successfully applied. It is noticeable that MESMA failed to map some particular areas. For instance, the paved roads were not mapped. This occurrence is expected, since asphalt endmembers were not considered in the study. Also, MESMA failed to map some areas dominated by bare soil, especially those associated with human settlements. The results show that the approach used in this study provides a promising technique for subpixel quantification of land cover types in southern Africa's savanna using Landsat 8 OLI imagery.

In comparison to traditional pixel based remote sensing techniques, which assign each pixel to a single class, MESMA provides a more nuanced quantification of land cover classes by providing estimates in a subpixel level. This property is especially important for highly heterogeneous areas, where the occurrence of more than one kind of land cover inside a single pixel is common. Among other heterogeneous environments in 
which MESMA has been successfully applied are urban areas (Powell et al. 2007; Wu, Deng and Jia 2014), wetlands (Robertson, King and Davies), the Californian chaparral (Roberts et al.) and savannas (Mishra, Crews and Okin, 2014). As such, MESMA, as a sub-pixel remote sensing approach, provides a promising path towards approaching challenges imposed by heterogeneous landscapes concerning the quantification of land cover types.

Previous work highlights the applicability of MESMA to quantify PV, NPV and B at a subpixel level in savanna environments (Mishra, Crews and Okin 2014; Meyer and Okin 2015). Such studies show that the subpixel approach is appealing to tease out the above mentioned land cover classes by using multispectral data. However, the scholars found that MESMA presented a greater accuracy in estimating the PV fractions, while in this research better accuracy was shown with the B fraction. It is important to highlight that these previous studies took place in the Kalahari savanna region of southern Africa, and thus, their results are dependent of particular characteristics of this area. In this sense, the discrepancies observed between my results and those of previous researches may not only be due to methodological differences, but to the characteristics of the respective study areas.

Another major factor that influenced the outcomes of this research was the nature of the endmembers used to perform the analysis. The observed inefficiency of MESMA in bare areas might indicate that the chosen B endmembers do not encompass the total spectral variability found in the study area's soil. In this sense, it is recognizable that MESMA failed to map very bright areas in the landscape with very sandy soil and minimal vegetation cover. Another aspect that may have influenced the obtained results 
is the high content of bare soil observed in NPV endmembers. None of the selected NPV endmembers were, in fact, pure pixels. This is due because the grass cover in the study area is not dense enough to completely cover the surface and provide a "pure" spectral value. A similar mixing process occurs for PV endmembers, but concerning shade. The Landsat pixels that are completely covered by PV have an inherent proportion of shade, since higher trees and shrubs project shadows over lower vegetation extracts. Also, the obtained shade fractions are perceptibly higher in the regions near the flood plain, which might indicate a certain confusion between shade and soil moisture.

The methodology used in this study was to collect endmembers in pure pixels identified in the Landsat data. This selection process was chosen not only because it was the only available resource to do so, but because image derived endmembers carries spectral responses in the same scale of the original data (Myint and Okin 2009). The application of alternative methodologies for endmember selection such as field or laboratory measurements (Somers et al. 2011) would provide different endmembers, influencing in the obtained results. In this sense, despite the advantages of using endmembers derived from the image to be unmixed, the use of field or laboratory collected endmembers would, potentially, eliminate the undesirable mixture that occurs for a theoretically pure pixel in the image. Also the inclusion of endmembers representing additional classes in the analysis might improve MESMA's performance. Although VIPER Tools limits the number of endmembers to 3, plus a shade endmember, it is possible to divide the study area in sub-regions to be analyzed individually, encompassing all the desirable classes (Myint and Okin 2009). So, in order to improve on 
the results here obtained, a deeper investigation to select the most adequate endmembers to be used in the analysis would be needed.

The hypothesis that MESMA would provide results that effectively depict the fractional land cover of the study area in a subpixel level was rejected. Part of the failure to adequately account for fractional land cover may have been due to the implemented validation methodology. The accuracy assessment process carried great subjectivity, since it highly relies on human visual image interpretation. In this sense, both the results and their validation are biased and present errors. Another aspect that can lead to an augmenting of the imprecision of the accuracy assessment is the large difference of spatial resolution between Landsat 8 OLI and Worldview-2 data. In such a context, the admitted georreferencing error for Landsat is 15 meters, while for Worldview it is 0.25 meters. So, it is impossible to guarantee the required positioning exactness of the overlaid data for validation purposes. However, this validation methodology was chosen because it was the only available resource to perform the accuracy assessment of the results. To improve the validation process, one good option would be to implement an infield spectra collection to serve as ground truth data (Blanco et al. 2014). Another alternative to the visual validation methodology would be to compare the results with accurate fractional images derived from high spatial resolution data (Mishra, Crews and Okin 2014). The limitations identified in the accuracy assessment method used in this study show that, in the future, the improvement of this process may lead to the acceptance of the stated hypothesis.

The relevance of this study relies, mainly, in the ecological importance of the Mayuni Conservancy. Besides falling centrally in KAZA, the study area is a seasonal 
migration corridor for native wildlife that moves across international boundaries (Naidoo et al. 2012). Also, this communal conservancy stands as a symbol of a great shift in land management policies in Namibia after its independence in 1990. These areas are characterized by the empowerment of local communities, which are engaged in managing and distributing benefits from wildlife resources in their areas. Before that, the region was distressed by military occupation, extensive poaching and a severe drought. Now, in conservancies, wildlife is livelihood asset and poaching is no longer accepted, which contributes to the restoration of local and regional ecosystems (World Wildlife Fund 2016). So, the research of methods to better quantify land cover classes in these areas has great value, once the knowledge about the landscape dynamics aids to identify areas that are more prone to activities and to develop sustainable management strategies. 


\section{CONCLUSION}

This study investigates the applicability of MESMA on Landsat 8 OLI data for quantifying land cover types in the Mayuni Conservancy, northeastern Namibia. To do so, an investigation was conducted in order to find the best endmembers selection methodology possible as well as to define the correct parameters to run the analysis. This research is justified by the inherent complexity of remote-sensing based characterization of savannas. Due to the high heterogeneity of the land cover in these ecosystems, which leads to the mixing of different land cover types at a subpixel level, traditional remote sensing classification methods present low effectiveness in mapping such areas in a quantitatively manner. In such a context, spectral unmixing techniques rise as a promising alternative to perform this task. The research of methods to more accurately assess the land cover of these environments is relevant not only because the unique ecologic characteristics of savannas but, also, due to the vast distribution of these ecosystems across the globe.

The knowledge about the land cover composition of southern Africa's savannas is fundamental to tracing management strategies in order to promote the sustainable development of the region, which is characterized by the coexistence and codependence of human activities and biological resources. Falling centrally on the Kavango-Zambezi Transfrontier Conservation Area (KAZA), the study area is representative of the international preservation zone concerning land cover types and ecological characteristics. 
The outcomes of this thesis provide subsidies for future research using spectral unmixing techniques applied on multispectral data for the study area and its surroundings. In fact, expanding the study area is a promising future direction to be taken under the scope of this study. Among the next steps to be taken, one of the most important is the inclusion of a historic series of Landsat data in the analysis, which can provide valuable information about the region's ongoing landscape changings. With the addition of this multi-temporal component, it will be possible to assess how climatic and anthropogenic drivers affect the vegetation dynamics of the study area, since the research conducted here points out that these factors have a great weight in the transformation of the region's landscape. In such a context, it is known that savannas are affected by climate, especially regarding rainfall and moisture availability (Scholes and Archer 1997), and that the region in which the study area is located is getting drier over time (Gaughan and Waylen 2012). Also, the human population and wildlife growth in southern Africa's savannas, together with enduring livestock farming activities, submits the natural vegetation to great pressure (Scholes and Archer 1997).

The conclusion to be drawn from this study is that, despite the results of the accuracy assessment, MESMA's adequacy for mapping land cover in southern Africa's savannas using Landsat 8 data cannot be completely refuted. In this sense, the thesis lacks a validation method that is able to confirm the veracity of the results with acceptable certainty. This study is characterized by its evaluative trait and explores many aspects of MESMA applied on multispectral data. Although the accuracy verification was not very encouraging, the results look promising and worthy of a more appropriate validation further ahead, such as the use of field data or algorithms applied to the available data. The 
investigation of parameters used for the analysis is a key aspect in future research on MESMA. In this sense, the refinement of such parameters has the potential to enhance the analysis performance concerning the total area mapped. The outcomes of this study are not limited to its results only.

This thesis must be interpreted, also, as methodology test that, instead of providing definitive answers, leads to reflection on the importance of the definition of parameters for MESMA processing and on the analysis of its results. Future steps in this research must be taken towards enhancing the analysis' efficiency and the validation of the results, as well as expanding the study area to vaster regions in the same ecosystem. 


\section{REFERENCES}

Adeel, Z., G. De Kalbermatten, and M. E. Assessment. 2005. Ecosystems and human well-Being: Desertification Synthesis. Washington, DC: World Resource Institute.

Asner, G. P. and D. B. Lobell. 2000. A biogeophysical approach for automated SWIR unmixing of soils and vegetation. Remote Sensing of Environment 74(1): 99-112.

Asner, G. P. and K. B. Heidebrecht. 2002. Spectral unmixing of vegetation, soil and dry carbon cover in arid regions: comparing multispectral and hyperspectral observations. International Journal of Remote Sensing 23 (19): 3939-3958.

Blanco, P. D., H. F. del Valle, P. J. Bouza, G. I. Metternicht and L. A. Hardtke. 2014. Ecological site classification of semiarid rangelands: synergistic use of Landsat and Hyperion imagery. International Journal of Applied Earth Observation and Geoinformation 29: 11-21.

Blaum, N., E. Rossmanith, and F. Jeltsch. 2007. Land use affects rodent communities in Kalahari savanna rangelands. African Journal of Ecology 45: 189-195.

Bond, W. J. and Keeley, J. E. 2005. Fire as a global 'herbivore': the ecology and evolution of flammable ecosystems. Trends in Ecology and Evolution 20(7): 387394.

Campos-Bescós M. A., R. Muñoz-Carpena, D. Kaplan, J. Southwoth, L. Zhu and P. R. Waylen. 2013. Beyond precipitation: Physiographic gradients dictate the relative importance of environmental drivers on savanna vegetation. PLOS ONE 8: 1-15.

Combe, J., S. Le Mouelic, C. Sotin, A. Gendrin, J. F. Mustard, L. Le Deit, P. Launeau, J. P. Birbring, B. Gondet, Y. Langevin, and P. Pinet. 2008. Analysis of OMEGA/Mars Express data hyperspectral data using a multiple-endmember linear spectral unmixing model (MELSUM): Methodology and first results. Planetary and Space Science 56: 951-975.

Cumming, D. H. M. 1982. The influence of large herbivores on savanna structure in Africa. In Ecology of Tropical Savannas, ed. Huntley, B. J. and B. H. Walker, 217-245.

Dube, O. P. and Pickup, G. 2001. Effects of rainfall variability and communal and semicommercial grazing on land cover in southern African rangelands. Climate Research 17: 195-208. 
Ehlers, M., S. Klonus, P. J. Åstrand and P. Rosso. 2010. Multi-sensor fusion for pansharpening in remote sensing. International Journal of Image and Data Fusion 1(1): 25-45.Eitel, J. U. H., D. S. Long, P. E. Gessler and A. M. S. Smith. 2007. Using in-situ measurements to evaluate the new RapidEye satellite series for prediction of wheat nitrogen status. International Journal of Remote Sensing 28(18): 4183-4190.

Fasial, K. and A. Shaker. 2014. The use of remote sensing technique to predict gross domestic product (GDP): An analysis of built-up index and GDP in nine major cities in Canada. The Internation Achives of the Photogrammetry, Remote Sensing and Spatial Information Sciences 60(7): 85-92.

Fernández-Manso, A., C. Quintano, and D. Roberts. 2012. Evaluation of potential of multiple endmember spectral mixture analysis (MESMA) for surface coal mining affected area mapping in different world forest ecosystems. Remote Sensing of Environment 127: 181-193.

Franke, J., D. A. Roberts, K. Halligan and G. Menz. 2009. Hierarchical multiple endmember spectral mixture analysis (MESMA) of hyperspectral imagery for urban environments. Remote Sensing of Environment 113: 1712-1733.

Garcia-Haro, F., M. Gilabert, and J. Melia. 1996. Linear spectral mixture modelling to estimate vegetation amount from optical spectral data. International Journal of Remote Sensing 17: 3373-3400.

Gaughan, A. E. and P. R. Waylen. 2012. Spatial and temporal precipitation variability in the Okavango-Kwando-Zambezi catchment, southern Africa. Journal of Arid Environments 82: 19-30.

Green, A. A., M. Berman, P. Swtzer and M. D. Craig. 1988. A transformation for ordering multispectral data in terms of image quality with implication for noise removal. IEEE Transactions on Geoscience and Remote Sensing26(1): 65-74.

Guerschman, J. P., M. J. Hill, L. J. Renzullo, D. J. Barrett, A. S. Marks, and E. J. Botha. 2009. Estimating fractional cover of photosynthetic vegetation, nonphotosynthetic vegetation and bare soil in the Australian tropical savanna region upscaling the EO-1 Hyperion and MODIS sensors. Remote Sensing of Environment 113: 928-945.

Herold, M., P. Mayaux, C. E. Woodcock, A. Baccini, and C. Schmullius. 2008. Some challenges in global land cover mapping: An assessment of agreement and accuracy in existing $1 \mathrm{~km}$ datasets. Remote Sensing of Environment 112: 25382556.

Jensen, J. R. 2014. Introductory digital image processing: A remote sensing perspective $4^{\text {th }}$ edition. Englewood Cliffs, NH: Prentice-hall. 
Jung, M., K. Henkel, M. Herold, and G. Churkina. 2006. Exploiting synergies of global land cover products for carbon cycle modeling. Remote Sensing of Environment 101: 534-553.

Kruse, F. A. and S. L. Perry. 2013. Mineral mapping using simulated Worldview-3 shortwave-infrared imagery. Remote Sensing 5: 2688-2703.

Kulkarni, A. V., S. K. Singh, P. Mathur and V. D. Mishra. 2006. Algorithm to monitor snow cover using AWiFS data of RESOURCESAT-1 for the Himalayan region. International Journal of Remote Sensing 27(12): 2449-2457.

Lim, H., Y. Seo, J. Na, S. Bang, J. Lee, J. Cho, J. H. Park and J. U. Park. 2010. Tracking capability analysis of ARGO-M satellite laser ranging system for STSAT-2 and KOMPSAT-5. Journal of Astronomy and Space Sciences 27(3): 245-252.

Lu, D. and Q. Weng. 2004. Spectral mixture analysis of the urban landscape in Indianapolis with Landsat ETM+ imagery. Photogrammetric Engineering \& Remote Sensing 70(9): 1053-1062.

McNaughton, S. J. 1983. Serengeti grassland ecology: the role of composite environmental factors and contingency in community organization. Ecological Monographs by the Ecological Society of America 53(3): 291-320.

Meyer, T. and G. S. Okin. 2015. Evaluation of spectral unmixing techniques using MODIS in a structurally complex savanna environment for retrieval of green vegetation, nonphotosynthetic vegetation, and soil fractional cover. Remote Sensing of Environment 161: 122-130.

Michishita, R., P. Gong, and B. Xu. 2012. Spectral mixture analysis for bi-sensor wetland mapping using Landsat TM and Terra MODIS data. International Journal of Remote Sensing 33(11): 3373-3401.

Mishra, N. B., K. A. Crews, and G. S. Okin. 2014. Relating spatial patterns of fractional land cover to savanna vegetation morphology using Multi-scale Remote Sensing in the central Kalahari. International Journal of Remote Sensing 35: 2082-104.

Mitchel, A. 2009. The Esri Guide to GIS Analysis - Volume 2: Spatial Measurements \& Statistics. Redlands, CA: Esri press.

Munyati, C. and Ratshibvumo. 2011. Characterizing vegetation cover in relation to land use in the Inkomat catchment, South Africa, using Landsat imagery. Area 43(2): $189-201$.

Müller, H., P. Rufin, P. Griffths, A. B. Siqueira, and P. Hostert. 2015. Mining dense Landsat time series for separating cropland and pasture in a heterogeneous Brazilian savanna landscape. Remote Sensing of Environment 156: 490-499 
Myint S. W., and G. S. Okin. 2009. Modelling land-cover types using multiple endmember spectral mixture analysis in a desert city. International Journal of Remote Sensing 30(9): 2237-2257.

NACSO - Namibian Association of Community Based Natural Resource Management Support Organizations. 2012. Living with wildlife - the story of Mudumu North Complex. Winhoek, Namibia.

Naidoo, R., P.D Preez, G. Stuart-Hill, M. Jago and M. Wegmann. 2012. Home of the Range: Factors explaining partial migration of African Buffalo in a tropical environment. PLoS ONE 7(5): 1-11.

Nagler, P. L., Y. Inoue, E. P. Glenn, A. L. Russ, and C. S. T. Daughtry. 2003. Cellulose Absorption Index (CAI) to quantify mixed soil-plant litter scenes. Remote Sensing of Environment 87: 310-325.

Nogueira, S. F., G. Bayma-Silva, G. P. Mateus, D. C. Victioria, R. G. Andrade, J. A. A. Demarchi. 2015. Avaliação do modelo de mistura espectral com múltiplos componentes (MESMA) na discriminação de diferentes condições de cobertura em pastagens. Anais XVII Simpósio Brasileiro de Sensoriamento Remoto 17: 2544-2551.

Okin, G. S., D. A. Roberts, B. Murray, and W. J. Okin. 2001. Practical limits on hyperspectral vegetation discrimination in arid and semiarid environments. Remote Sensing of Environment 77: 212-225.

Okin, G. S., K. D. Clarke, and M. M. Lewis. 2013. Comparison of methods for estimation of absolute vegetation and soil fractional cover using MODIS normalized BRDFadjusted reflectance data. Remote Sensing of Environment 130: 266-279.

Palmer, A. R. and A. F. van Rooyen. 1998. Detecting vegetation change in the southern Kalahari using Landsat TM data. Journal of Arid Environments 39(2): 143-153.

Powell, R. L., D. A. Roberts, P. E. Dennison, and L. L. Hess. 2007. Sub-pixel mapping of urban land cover using multiple endmember spectral mixture analysis: Manaus, Brazil. Remote Sensing of Environment 106: 253-267.

Roberts, D. A., K. Halligan, and P. E. Dennison. 2007. VIPER Tools User manual version 1.5. Licensed under the Creative Commons Attribution-NoncommercialShare Alike 3.0 Unported License.

Roberts, D. A., M. Gardner, R. Church, S. Ustin, G. Scheer, and R.O. Green. 1998. Mapping Chaparral in the Santa Monica Mountains using multiple endmember spectral mixture models. Remote Sensing of Environment 65: 267-279. 
Robertson, L. D., D. J. King, and C. Davies. 2015. Assessing land cover change and anthropogenic disturbance in wetlands using vegetation fractions derived from Landsat 5 TM imagery (1984-2010). Wetlands 1-15.

Roth, K. L., P. E. Dennison and D. A. Roberts. 2012. Comparing endmember selection techniques for accurate mapping of plant species and land cover using imaging spectrometer data. Remote Sensing of Environment 127: 139-152.

Sande, C. J., S. M. Jong and A. P. J. Roo. A segmentation and classification approach of IKONOS-2 imagery for land cover mapping to assist flood risk and flood damage assessment. Internation Journal of Applied Earth Observation and Geoinformation 4: 217-229.

Sankaran, M., N. P. Hanan, R. J. Scholes, J. Ratnam, D. J. Augustine, B. S. Cade, J. Gignoux, S. I. Higgins, X. Le Roux, F. Ludwig, J. Ardo, F. Banyikwa, A. Bronn, G. Bucini, K. K. Caylor, M. B. Coughenour, A. Diouf, W. Ekaya, C. J. Feral, E. C. February, P. G. H. Frost, P. Hiernaux, H. Hrabar, K. L. Metzger, H. H. T. Prins, S. Ringrose, W. Sea, J. Tews, J. Worden, and N. Zambatis . 2005. Determinants of woody cover in African savannas. Nature 438: 846-849.

Scanlon, T. M., J. D. Albertson, K. K. Caylor, and C. A. Williams. 2002. Determining land surface fractional cover from NDVI and rainfall time series for a savanna ecosystem. Remote Sensing of Environment. 82: 376-388.

Scholes, R. J. and B. H. Walker. 2004. An African savanna: Synthesis of the Nylsvley study. Cambridge, UK: Cambridge University Press.

Scholes, R. J. and S. R. Archer. 1997. Tree-grass interactions in savannas. Annual Review of Ecology and Systematics 28: 517-544.

Scovronick, N., H. Gordon, and J. Turpie. 2007. Socio-economic baseline survey of selected communities within the Kavango-Zambezi Transfrontier Conservation Area. Conservation International Report.

Settle, J. J and N. A. Drake. 1993. Linear mixing and the estimation of ground cover proportions. International Journal of Remote Sensing 14: 1159-1177.

Shang, J., J. Liu, B. Ma, T. Zhao, X. Jiao, X. Geng, T. Huffman, J. M. Kovacs and D. Walters. 2015. Mapping spatial variability of crop growth using RapidEye data in Northern Ontario, Canada. Remote Sensing of Environment 168: 113-125.

Shapiro, C., L. Nijsten, S. Schmitt, and P. Tibaldeschi. 2015. GLOBIL: WWF's global observation and biodiversity information portal. The International Archives of the Photogrammetry, Remote Sensing and Spatial Information Sciences 40(7): 511514. 
Small, C. 2004. The Landsat ETM+ spectral mixing space. Remote Sensing of Environment 93: 1-17.

Smith, M. J. and C. F. Pain. 2009. Applications of remote sensing in geomorphology. Progress in Physical Geography 33(4): 568-582.

Somers, B., G. P. Asner, L. Tits, and P. Coppin. 2011. Endmember variability in spectral mixture analysis: A review. Remote Sensing of Environment 115: 1603-1616.

Somers, B., J. Verbesselt, E. M. Ampe, N. Sims, W W. Vetraeten, and P. Coppin. 2010. Spectral mixture analysis to monitor defoliation in mixed-aged Eucalyptus globulus labill Plantations in Southern Australia using Landsat 5-TM and EO-1 Hyperion Data. International Journal of Applied Earth Observation and Geoinformation 12: 270-77.

Somers, B., K. Cools, S. Delalieux, J. Struckens, D. Van de Zande, W. W. Vertraeten, P. Coppin. 2009. Nonlinear hyperspectral mixture analysis for tree cover estimates in orchards. Remote Sensing of Environment 113: 1183-1193.

Stott, P. 1991. Recent trends in the ecology and management of the World's savanna formations. Progress in Physical Geography 15: 18-28.

Toutin, T. 2004. Comparison of stereo-extracted DTM from different high-resolution sensors: SPOT-5, EROS-A, IKONOS-II and QuickBird. Transactions on Geoscience and Remote Sensing 42(10): 2121-2129.

Tucker C. J., J. R. G Townshend, and T. E. Goff. 1985. African land-cover classification using satellite data. Science 227 369-375.

USGS. 2015. Landsat Missions - Landsat 8. Available at landsat.usgs.gov/landsat8.php (last accessed 14 February 2016).

White, J. C., N. C. Coops, T. Hilker, M. A. Wulder and A. L. Carroll. 2007. Detecting mountain pine beetle red attach damage with EO-1 Hyperion moisture indices. International Journal of Remote Sensing 10: 2111-2121.

World Wildlife Fund. 2016. Conserving wildlife and enabling communities in Namibia. Available at http://www.worldwildlife.org/projects/conserving-wildlife-andenabling-communities-in-namibia (last accessed 17 April 2016).

Wu, C., C. Deng, and X. Jia. 2014. Spatially constrained multiple endmember spectral mixture analysis for quantifying subpixel urban impervious surfaces. Journal of Selected Topics in Applied Earth Observations and Remote Sensing 7(6): 19761984. 
Wu, C. and A. Murray. 2003. Estimating impervious surface distribution by spectra mixture analysis. Remote Sensing of Environment 84: 493-505.

Yang, J., P. J. Weisberg, and N. A. Bristow. 2012. Landsat remote sensing approaches for monitoring long-term tree cover dynamics in semi-arid woodlands: Comparison of vegetation indices and spectral mixture analysis. Remote Sensing of Environment 119: 62-71. 


\section{CURRICULUM VITA}

NAME: $\quad$ Fernando Ferreira Caixeta

ADRESS: $\quad 400$ W. Bloom St. apt. 10

Louisville, KY 40208

DOB: $\quad$ Brasília, Distrito Federal, Brazil - April 10, 1981

EDUCATION

\& TRANING: $\quad$ B.A, Forestry Engineering Universidade de Brasília, $2001-2007$

AWARDS: Out-of-State Merit Scholar Award

University of Louisville

2014

Outstanding Graduate in Geography Award

University of Louisville

2016

PROFESSIONAL SOCIETIES: Conselho Regional de Engenharia e Arquitetura do Distrito Federal - CREA/DF

NATIONAL MEETING PRESENTATIONS: The use of Multiple Endmember Spectral Mixture Analysis applied to Landsat imagery in the Mudumu North Complex, Namibia (1990-2014).

American Association of Geographers Annual Meeting.

San Francisco, CA

April 1 ${ }^{\text {st }}, 2016$ 